ESTUDIO

\title{
LA INDUSTRIA DEL PETRÓLEO EN CHILE*
}

\author{
Claudio A. Agostini \\ y Eduardo Saavedra
}

\begin{abstract}
Este artículo describe y caracteriza, desde el punto de vista de su organización industrial, los mercados del petróleo y sus derivados líquidos en Chile. Con ese objetivo, se realiza primero una descripción sistemática de cada uno de los mercados que componen esta industria, considerando para ello la estructura vertical de la industria que permite que el insumo básico proveniente de la naturaleza llegue al usuario final: exploración, producción de crudo, importación de crudo, refinación, almacenamiento, transporte y distribución mayorista y minorista. Posteriormente, se realiza un análisis de organización industrial que, a partir de los niveles de concentración y
\end{abstract}

Claudio A. Agostini. Doctor en Economía, University of Michigan. Profesor Asociado, ILADES-Universidad Alberto Hurtado. E-mail: agostini@uahurtado.cl.

Eduardo SaAvedra. Doctor en Economía, Cornell University. Profesor Asociado, ILADES-Universidad Alberto Hurtado. Email: saavedra@uahurtado.cl.

* Este artículo está basado parcialmente en un trabajo no publicado, realizado por estos autores en el año 2004 para la Comisión Nacional de Energía. Sin embargo, los autores son los únicos responsables de las opiniones y conclusiones de este artículo. Agradecemos los comentarios de Soledad Arellano y los participantes de un seminario realizado en el Centro de Estudios Públicos y la valiosa asistencia de Manuel Délano. 
los grados de integración vertical y competencia, identifica posibles conductas anticompetitivas en la industria. Finalmente, se entregan recomendaciones de política pública en aspectos que requieren medidas de corrección o perfeccionamiento para garantizar la competencia. Los autores se inclinan por sugerir una ley marco que proteja la competencia en la industria y la libertad de entrada en segmentos de mercado que pueden operar competitivamente, con la debida tutela de las autoridades correspondientes, pero con un mínimo de regulación sectorial.

Palabras clave: Combustibles líquidos, petróleo, organización industrial, Chile.

Clasificación JEL: L11, L22, L40, L72.

\section{INTRODUCCIÓN}

\section{耳}

sector hidrocarburos tiene un rol crucial en la producción de energía en Chile, siendo el sector más relevante desde el punto de vista de las energías primarias dentro de la matriz energética. De acuerdo a la Comisión Nacional de Energía (CNE), el consumo neto de hidrocarburos correspondió al 67\% del consumo primario de energía del 2007. Si se mira al interior de este sector, el consumo neto de petróleo y sus derivados llegó a un 41\%, mientras que el de gas natural correspondió al $16 \%$. La industria del petróleo entonces, al tener un peso tan importante en la producción energética, tiene una influencia significativa sobre la capacidad productiva del país, ya que la energía sigue siendo uno de los principales insumos en los procesos productivos que se utilizan en Chile. Por esta razón, resulta particularmente importante que los distintos mercados que componen la industria funcionen en forma competitiva, ya que ello permite la asignación eficiente de los recursos.

Con el objetivo de evaluar el funcionamiento de la industria y considerar una política pública que garantice la libre competencia, este artículo caracteriza la industria del petróleo y sus combustibles líquidos desde el punto de vista de su organización industrial. Para ello, se identifican los niveles de concentración en la propiedad, los grados de 
integración vertical y competencia en los distintos mercados que la componen y se analizan los riesgos de potenciales conductas anticompetitivas. Como resultado, se establecen los elementos básicos que debiera contener una ley que norme esta industria, de modo de minimizar los incentivos para la existencia de conductas anticompetitivas en los mercados, garantizando de este modo que los precios reflejen los costos efectivos de proveer los bienes o servicios al consumidor.

Este trabajo no es el primero en realizar un análisis de la industria del petróleo en Chile. En particular, el trabajo de Arellano y Valdés (2006) estudia la industria de combustibles líquidos y entrega una mirada respecto a algunas preocupaciones de organización industrial en los mercados que la componen, siendo en tal sentido un sustituto parcial de este trabajo.

Si bien una nueva mirada a la industria de hidrocarburos como un todo sería deseable desde el punto de vista de la complementariedad, y sustituibilidad, que razonablemente hay entre el gas natural y los derivados del petróleo, por razones de comprensión, acceso a información y sobre todo de homogeneidad del trabajo, es que se excluye del análisis a los mercados del gas natural. De igual forma, se ha dejado fuera el mercado del gas licuado ya que éste es en términos económicos mucho más cercano al de gas natural que al del petróleo y sus derivados líquidos ${ }^{1}$.

La estructura de este artículo es la siguiente. La sección dos describe la estructura y las relaciones patrimoniales en la industria. La sección tres describe la evolución de los precios.. En la sección cuatro se realiza un detallado análisis de organización industrial de los mercados que componen la industria del petróleo en Chile. Finalmente, la sección cinco concluye con recomendaciones de política para el sector.

\section{ESTRUCTURA DE LA INDUSTRIA}

Se describe a continuación la estructura de la industria, analizando por separado cada mercado relevante, así como las relaciones patrimoniales existentes en los mercados del petróleo y sus derivados líquidos.

${ }^{1}$ Un análisis de la organización industrial de la industria del gas natural, y sus interacciones con el gas licuado derivado del petróleo, se encuentra en Fosco y Saavedra (2003a, 2003b y 2003c) y Galetovic (2008). 
La Figura $\mathrm{N}^{\circ} 1$ presenta el esquema de funcionamiento de la industria del petróleo y sus respectivos mercados. En términos generales, se separan las actividades que comprenden el upstream, incluyendo la exploración, extracción, producción de petróleo crudo, de las downstream, que comprenden la refinación del petróleo crudo, almacenamiento y transporte de combustibles, distribución de combustibles a nivel mayorista y nivel minorista, culminando la cadena de la industria en los consumidores finales.

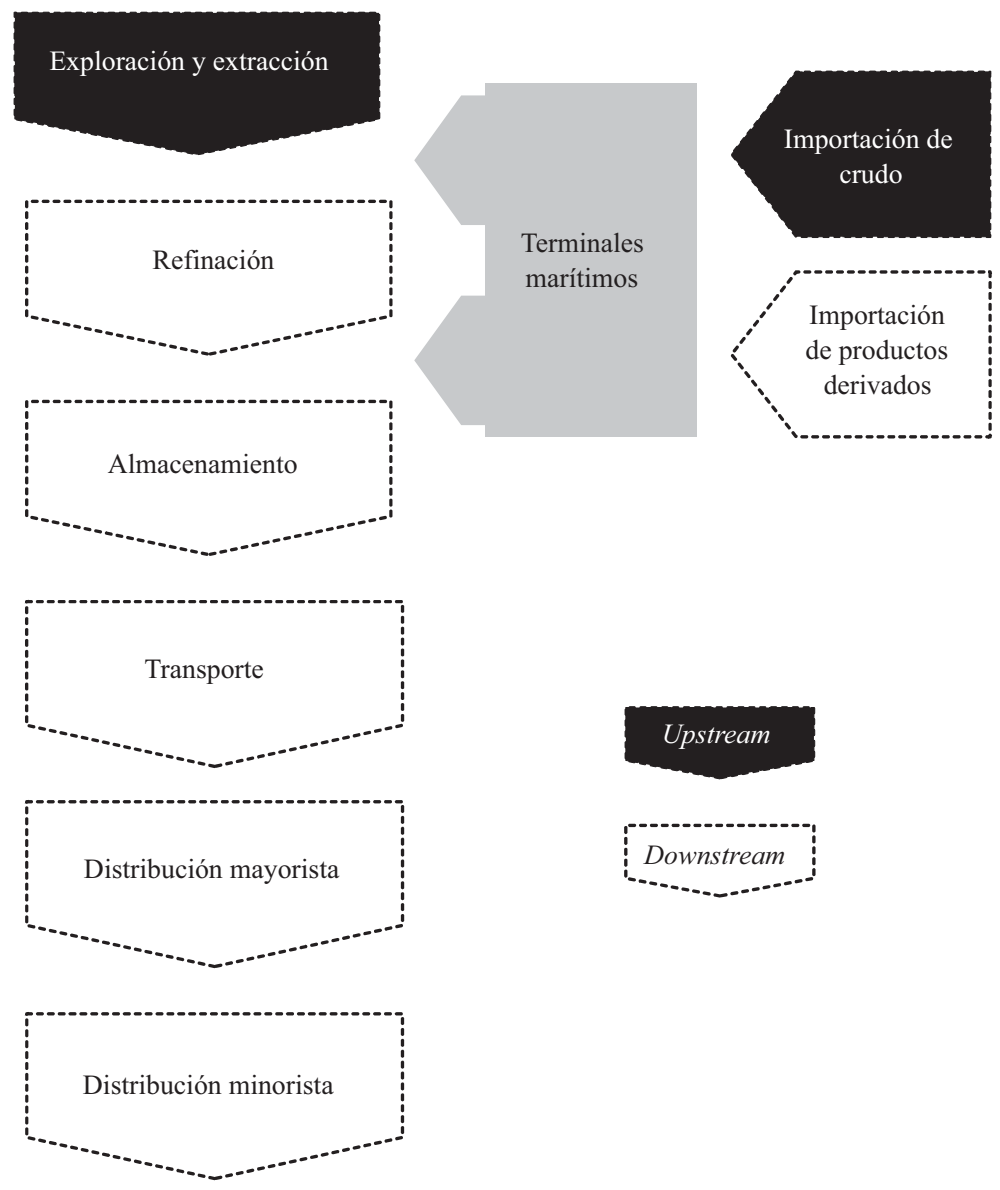




\subsection{Actividades upstream}

En este segmento de la industria, la Empresa Nacional del Petróleo (Enap) tiene un rol preponderante ya que es la única empresa que produce y refina petróleo crudo en Chile. Fue fundada el 19 de junio de 1950 para explotar los yacimientos de hidrocarburos de la Región de Magallanes y tiene una participación en el mercado mayorista de combustibles líquidos en torno al 85\%.

En el mercado de exploración y extracción de petróleo crudo, los yacimientos petrolíferos descubiertos en Chile están concentrados en la Cuenca de Magallanes, en tres zonas denominadas "Distritos": continente, isla Tierra del Fuego y costa afuera. Actualmente la mayor producción de petróleo crudo y gas natural proviene de los yacimientos costa afuera, que fueron desarrollados a partir de la década de los ochenta. Sin embargo, la producción de petróleo crudo ha caído en forma significativa a lo largo del tiempo pasando de $2.401 \mathrm{Mm}^{3}$ en 1981 a $148 \mathrm{Mm}^{3}$ en el 2007.

Un elemento importante de considerar en el análisis de este mercado es que todos los yacimientos petrolíferos que se encuentren en el territorio nacional son de propiedad del Estado².

Las reformas estructurales en este mercado comenzaron a fines de la década de los setenta. En 1975 se permitió que el Estado pudiera ejercer la facultad de explotar los yacimientos petrolíferos no sólo a través de la Enap directamente, sino que también a través de concesiones administrativas a terceros o bien mediante contratos especiales de operación petrolera (Ceop). Luego en 1978, se liberalizó la distribución mayorista, y así como importaciones y exportaciones de crudo y derivados. Finalmente, en 1982 se estableció la libertad de precios de los derivados del petróleo. El impacto de estas reformas se tradujo, entre otras cosas, en el ingreso de empresas privadas a la exploración en asociación con Enap como también de nuevos actores en el mercado de distribución de combustibles.

Una característica importante del sector petrolero, entonces, es el potencial libre acceso del sector privado a la explotación y exploración, a la refinación y la distribución primaria y secundaria.

\footnotetext{
${ }^{2}$ La Constitución Política de 1980, en su Artículo 24, otorga al Estado “el dominio absoluto, exclusivo, inalienable e imprescriptible de todas las minas, comprendiéndose en éstas (...) los depósitos de carbón e hidrocarburos (...)”.
} 
Los contratos especiales de operación se firman entre un inversionista (nacional o extranjero) y el Estado para la exploración, explotación o beneficio de yacimientos. Estos contratos no afectan el dominio del Estado sobre los yacimientos, no constituyen concesiones, no confieren derechos sobre los hidrocarburos y no otorgan facultades de apropiación o aprovechamiento sobre ellos. El inversionista asume el riesgo exploratorio y recibe una retribución en dinero y especies (hidrocarburos) sujeta a impuestos (tasa máxima 50\%). Puede también ser autorizado expresamente para exportar los hidrocarburos que recibe, disponiendo libremente de las divisas generadas. Alternativamente, el Estado puede readquirir los hidrocarburos.

En la Tabla $\mathrm{N}^{\circ} 1$ se observa la evolución que han tenido los Ceop en el tiempo. Hasta el año 2006 se realizaron muy pocos contratos y en ellos siempre participó Enap. A fines de 2006 Enap finalizó un estudio sobre el potencial exploratorio de hidrocarburos en la cuenca de Magallanes, en el cual se identificaron once bloques que fueron rankeados de acuerdo a prioridades definidas por la misma Enap. Las zonas de primera prioridad son de exclusiva operación de Enap, mientras que las áreas de segunda, tercera y cuarta prioridad permiten el ingreso de privados para que participen en la exploración de hidrocarburos mediante la entrega de contratos especiales de operación (Ceop) por parte del ministerio de Minería y Energía.

Además de las prioridades, la Enap definió un área de exclusión correspondiente a las zonas donde actualmente tiene pozos e instalaciones productivas y que forman parte de su patrimonio. Las zonas de primera prioridad son: Lago Mercedes, Intracampos, Chañarcillo, Dorado-Riquelme, Arenal, Tranquilo y Marazzi-Río Hondo. Las zonas de segunda prioridad son: Coirón, Caupolicán y Lenga. En estas zonas ya se han desarrollado modelos de exploración que identifican un potencial atractivo en gas y/o petróleo y por ello la decisión de Enap es asociarse con empresas privadas desde el inicio de la campaña de exploración. Las zonas de tercera y cuarta prioridad son: Tranquilo, Otway, Rusfín, Brótula, Bahía Inútil, Isla Magdalena, Porvenir y Lago Blanco. En estas zonas no se ha identificado un potencial exploratorio atractivo por lo que la exploración la hace solamente el privado y Enap se deja la opción de incorporarse como socio en las etapas de desarrollo de los yacimientos que se descubran. 
TABLA N $N^{\circ}$ 1: $\quad$ CONTRATOS DE OPERACIÓN PETROLERA (CEOP)

\begin{tabular}{|c|c|c|c|}
\hline \multirow[t]{2}{*}{ Bloque } & \multicolumn{2}{|c|}{ Duración del Contrato } & \multirow[t]{2}{*}{ Participantes } \\
\hline & Desde & Hasta & \\
\hline $\begin{array}{l}\text { Chiloé - Golfo de Penas: } \\
\text { Plataforma Continental }\end{array}$ & $07 / 12 / 77$ & 09/07/82 & $\begin{array}{l}\text { Arco Petróleos Chile S.A. } \\
\text { Amerada Hess Petróleos Chile S.A. } \\
\text { Enap }\end{array}$ \\
\hline $\begin{array}{l}\text { Plataforma Continental Isla } \\
\text { Diego de Almagro }\end{array}$ & $21 / 12 / 78$ & 18/11/82 & $\begin{array}{l}\text { Phillips Petróleos Chile S.A. } \\
\text { Arco Petróleos Chile S.A. } \\
\text { Amerada Hess Petróleos Chile S.A. } \\
\text { Enap }\end{array}$ \\
\hline Salar de Atacama & $30 / 08 / 88$ & $29 / 08 / 91$ & $\begin{array}{l}\text { Chile Hunt Company } \\
\text { Enap }\end{array}$ \\
\hline Altiplano de Arica & $13 / 03 / 89$ & 06/09/98 & $\begin{array}{l}\text { Chile Hunt Company } \\
\text { Enap }\end{array}$ \\
\hline $\begin{array}{l}\text { San Pedro de Atacama } \\
\text { Imilac }\end{array}$ & $14 / 03 / 89$ & $13 / 03 / 90$ & $\begin{array}{l}\text { Pecten Chile Company } \\
\text { Enap }\end{array}$ \\
\hline Pampa de Chiu-Chiu & 09/05/89 & $01 / 12 / 91$ & $\begin{array}{l}\text { Eurocan (Bermuda) Limitada de Chile } \\
\text { Enap } \\
\text { Eurocan (Bermuda) Limitada de Chile }\end{array}$ \\
\hline $\begin{array}{l}\text { Salar de Pedernales - } \\
\text { Maricunga }\end{array}$ & $09 / 05 / 89$ & $31 / 08 / 91$ & $\begin{array}{l}\text { Hamilton Oil (Chile) CO. } \\
\text { Norcen International Ltd. (Chile) } \\
\text { Enap } \\
\text { Maxus Energy }\end{array}$ \\
\hline Salar Punta Negra & 09/08/89 & 08/08/91 & $\begin{array}{l}\text { Corporation, Inc. } \\
\text { Enap }\end{array}$ \\
\hline Lago Mercedes & & & $\begin{array}{l}\text { Texaco Exploration Lago Mercedes } \\
\text { Chile }\end{array}$ \\
\hline $\begin{array}{l}\text { Tierra del Fuego } \\
\text { Chile }\end{array}$ & $15 / 01 / 90$ & Vigente & $\begin{array}{l}\text { Aderman/Smith Chile Inc. Y Argerado } \\
\text { Enap }\end{array}$ \\
\hline Área de Arica & $23 / 05 / 91$ & $18 / 08 / 91$ & $\begin{array}{l}\text { Petresearch International (Chile) Inc. } \\
\text { Enap }\end{array}$ \\
\hline Altiplano Iquique & $25 / 10 / 91$ & $25 / 10 / 92$ & $\begin{array}{l}\text { Chile Hunt Company } \\
\text { Enap }\end{array}$ \\
\hline $\begin{array}{l}\text { Lago Blanco, } \\
\text { Tierra del Fuego }\end{array}$ & $14 / 02 / 92$ & 08/06/93 & $\begin{array}{l}\text { Aderman/Smith Chile Inc. } \\
\text { Enap }\end{array}$ \\
\hline Tamarugal Norte & 06/06/97 & 06/06/07 & $\begin{array}{l}\text { Evergreen Resources, Inc. } \\
\text { Enap }\end{array}$ \\
\hline Tamarugal Sur & 06/06/97 & 06/06/07 & $\begin{array}{l}\text { Evergreen Resources, Inc. } \\
\text { Enap }\end{array}$ \\
\hline Bloque Fell (Magallanes) & $\begin{array}{l}\text { 1ra. Fase: } 31 \frac{1}{2} \text { años } \\
\text { 2da. Fase: } 61 / 2 \text { años }\end{array}$ & & $\begin{array}{l}\text { Cordex Petreums Inc. } \\
\text { Enap }\end{array}$ \\
\hline Tranquilo & $\begin{array}{l}\text { 1era Fase } 3 \text { años } \\
\text { 2da Fase } 2 \text { años } \\
\text { 3era Fase } 2 \text { años }\end{array}$ & & Consorcio IPR-Manas \\
\hline Otway & $\begin{array}{l}\text { 1era Fase } 3 \text { años } \\
\text { 2da Fase } 2 \text { años } \\
\text { 3era Fase } 2 \text { años }\end{array}$ & & Total S.A. \\
\hline Russfin & $\begin{array}{l}\text { 1era Fase } 3 \text { años } \\
\text { 2da Fase } 2 \text { años } \\
\text { 3era Fase } 2 \text { años }\end{array}$ & & Apache \\
\hline Brótula & $\begin{array}{l}1 \text { era Fase } 3 \text { años } \\
\text { 2da Fase } 2 \text { años } \\
\text { 3era Fase } 2 \text { años }\end{array}$ & & Greymouth \\
\hline Isla Magdalena & $\begin{array}{l}\text { 1era Fase } 3 \text { años } \\
\text { 2da Fase } 2 \text { años } \\
\text { 3era Fase } 2 \text { años }\end{array}$ & & Greymouth \\
\hline Porvenir & $\begin{array}{l}\text { 1era Fase } 3 \text { años } \\
\text { 2da Fase } 2 \text { años } \\
\text { 3era Fase } 2 \text { años }\end{array}$ & & Greymouth \\
\hline Coirón & $\begin{array}{l}\text { 1era Fase } 3 \text { años } \\
\text { 2da Fase } 2 \text { años } \\
\text { 3era Fase } 2 \text { años }\end{array}$ & & $\begin{array}{l}\text { Pan American Energy LLC } \\
\text { Enap }\end{array}$ \\
\hline Caupolicán & $\begin{array}{l}\text { 1era Fase } 3 \text { años } \\
\text { 2da Fase } 2 \text { años } \\
\text { 3era Fase } 2 \text { años }\end{array}$ & & $\begin{array}{l}\text { Greymouth } \\
\text { Enap }\end{array}$ \\
\hline Lenga & $\begin{array}{l}\text { 1era Fase } 3 \text { años } \\
\text { 2da Fase } 2 \text { años } \\
\text { 3era Fase } 2 \text { años }\end{array}$ & & $\begin{array}{l}\text { Apache } \\
\text { Enap }\end{array}$ \\
\hline
\end{tabular}

Fuentes: Comisión Nacional de Energía (CNE) y Ministerio de Minería. 
En el segmento de producción de petróleo crudo, Enap es la única empresa productora de petróleo en el mercado chileno y cuenta con más de 3.000 pozos perforados (poco menos de 1/3 en ultramar). Sin embargo, su participación en actividades de dowstream y logística hacen que Enap, como un grupo de empresas integrado, constituya una red de negocios del área energética.

Desde 1981 y hasta fines de 2003, Enap operó con cuatro filiales más una unidad de negocios, organizadas por líneas de negocios en exploración y producción (Sipetrol S.A.); refinación, logística y comercialización (Petrox S.A., RPC S.A. y Emalco S.A.); y, Enap Magallanes, que si bien no es formalmente una filial, en la práctica opera como tal en la XII Región.

En enero de 2004 se reestructuró el holding, fusionando las filiales RPC S.A. y Petrox S.A., para dar origen a Enap Refinerías S.A. y luego en junio de 2004, Enap Refinerías S.A. adquirió los activos de Emalco S.A. De esta forma, el grupo de empresas Enap quedó conformado por dos filiales más una unidad de negocios: línea de negocios de exploración y producción (E\&P), Sipetrol S.A.; línea de negocios de refinación, logística y comercialización ( $\mathrm{R}, \mathrm{L} \& \mathrm{C})$, Enap Refinerías S.A.; y Enap Magallanes.

En mayo de 1990 se creó Sipetrol S.A. con el objeto de estudiar y analizar nuevos proyectos petroleros en el mundo. Cuenta con filiales en Argentina, Colombia, Ecuador, Reino Unido y Egipto, y además participa en exploración en Yemen e Irán a través de consorcios con otras empresas de la industria. En el Gráfico $N^{\circ} 1 \mathrm{~A}$ se observa la evolución para los últimos 10 años de la producción de Sipetrol S.A. en los distintos países donde opera. En el Gráfico $\mathrm{N}^{\circ} 1 \mathrm{~B}$ se muestra la participación de cada bloque petrolero en la producción total de petróleo de Sipetrol.

Si bien Enap es la única empresa que produce petróleo crudo en Chile, la importancia del petróleo doméstico en el mercado es menor ya que la gran mayoría del consumo interno se satisface con importaciones. Esto se debe a una constante caída en la producción nacional y a un notable aumento en el consumo del petróleo a partir de la segunda mitad de la década pasada. Tal como se observa en los Gráficos $\mathrm{N}^{\circ} 2 \mathrm{~A}$ y $\mathrm{N}^{\mathrm{o}} 2 \mathrm{~B}$, mientras la producción doméstica es cada vez menor, el consumo de petróleo crudo es cada vez mayor, incluso con una participación de 2/3 del total de energéticos consumidos en el país. 


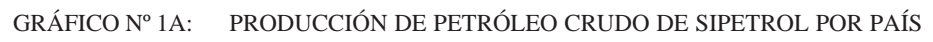
$\left(\mathrm{MM}^{3}\right)$ 1997-2007

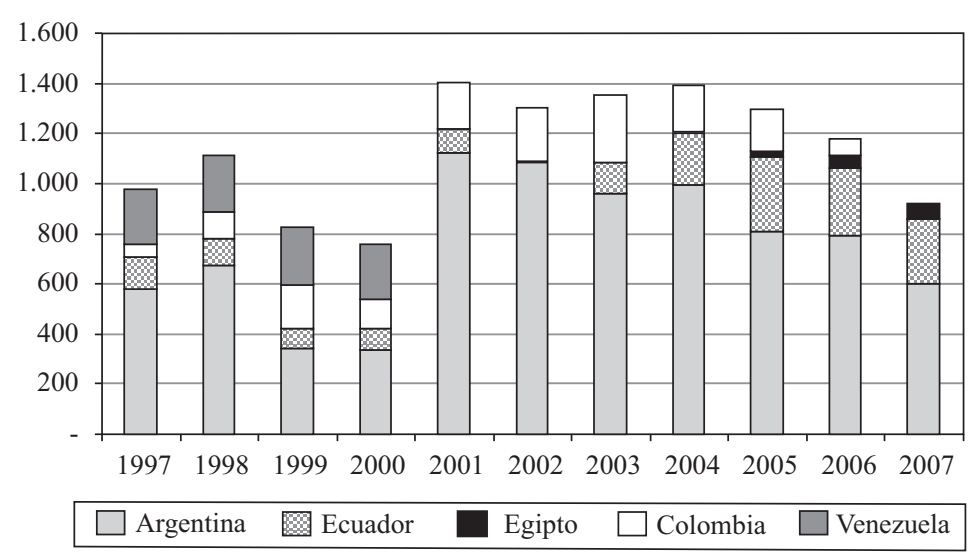

Fuente: Sipetrol S.A.

GRÁFICO N 1B: PARTICIPACIÓN DE LA PRODUCCIÓN DE PETRÓLEO POR BLOQUE (Año 2007)

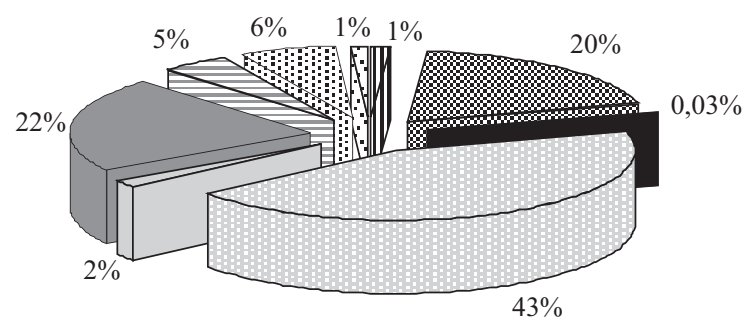

血 East R. Qattara 图 Flanco Norte $\quad$ Área Magallanes 䀧 Pampa Castillo $\square$ El Diyur $\square$ MDC $\quad$ North Bahariya 1 PBH

Fuente: Sipetrol S.A.

En la Tabla $N^{\circ} 2$ se muestra la oferta de petróleo crudo en Chile para el año 2007. No sólo destaca la mínima participación de la oferta nacional, sino que también la importancia adquirida por las importaciones vía marítima desde Brasil que constituyen el 31\% de la oferta total. Esto último contrasta con años anteriores, cuando más de 2/3 de las importaciones provenían de Argentina, mayoritariamente por medio de oleoductos. 
GRÁFICO N 2A: PRODUCCIÓN, CONSUMO E IMPORTACIONES DE PETRÓLEO CRUDO EN MM³. 1997-2007

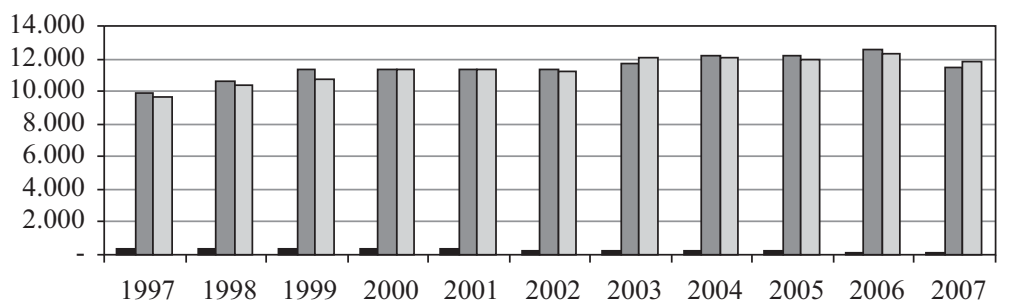

Producción $\square$ Consumo $\square$ Importaciones

Nota: Datos en teracalorías. El equivalente calórico para hidroelectricidad es de $2.504 \mathrm{KCal} / \mathrm{KWh}$. Fuente: Sipetrol S.A.

GRÁFICO No 2B: CONSUMO TOTAL DE ENERGÉTICOS PRIMARIOS POR FUENTE. (Año 2007)

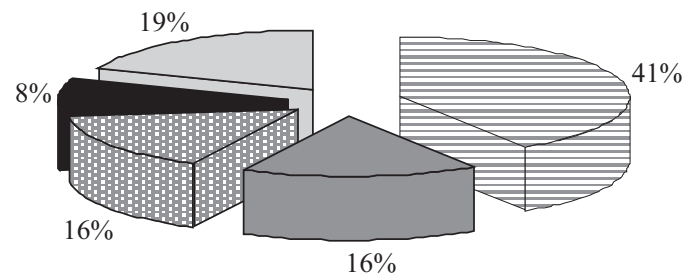

目 Petróleo crudo $\square$ Gas natural 圈 Carbón $\square$ Hidroelectricidad $\square$ Leña

Fuente: Comisión Nacional de Energía (CNE).

TABLA N ${ }^{\circ}$ 2: $\quad$ OFERTA DE PETRÓLEO CRUDO EN CHILE

(Año 2007)

\begin{tabular}{lrr}
\hline Origen & $\mathrm{Mm}^{3}$ & $\%$ \\
\hline Crudo nacional (ENAP Magallanes) & 147 & $1,2 \%$ \\
Crudo importado & 11.807 & $98,8 \%$ \\
- Brasil & 3.660 & \\
- Angola & 1.771 & \\
- Turquía & 1.653 & \\
- Ecuador & 1.653 & \\
- Otros orígenes & 3.070 & \\
\end{tabular}

Fuente: Comisión Nacional de Energía (CNE). 


\subsection{Actividades downstream: Refinación, almacenamiento y transporte}

En el análisis de downstream de la industria petrolera es importante examinar los grados de integración vertical entre los distintos mercados. En particular, es relevante considerar la potencial discriminación en el acceso que las pocas empresas participantes en los distintos mercados pueden ejercer sobre las potenciales firmas entrantes.

En la refinación de petróleo crudo, la producción interna es realizada exclusivamente por Enap con plantas propias, la que se complementa con importaciones que realizan la misma Enap y algunos distribuidores mayoristas. La refinería de petróleo ubicada en Concón comenzó sus operaciones en 1954 junto con el Terminal Quintero, que recibe petróleo crudo del Estrecho de Magallanes. En 1959 se construyó el Terminal Maipú, conectado por oleoducto con la refinería de Concón. Finalmente, en 1966 la Refinería Petrox comenzó a operar en Talcahuano. Enap realiza las actividades de refinación a través de estas dos plantas de Refinerías Enap S.A. y, en mucho menor medida, de su Planta Gregorio, ubicada en Magallanes.

Enap Refinería Bío Bío (ex Petrox) abastece aproximadamente al $40 \%$ del mercado nacional, siendo su capacidad de almacenamiento de petróleo crudo de aproximadamente $489 \mathrm{Mm}^{3}$ y su capacidad de refinación en la actualidad de 18 mil m³ por día. Enap Refinerías Aconcagua (ex R.P.C.) posee una capacidad de almacenamiento de crudo de aproximadamente $452 \mathrm{Mm}^{3}$, con una capacidad de refinación actual de $16.330 \mathrm{~m}^{3}$ por día. La producción de la refinería satisface alrededor del $40 \%$ del mercado nacional de combustibles. Finalmente, la Refinería Gregorio-Magallanes posee una capacidad de almacenamiento de crudo de aproximadamente 221 mil metros cúbicos. El proceso de fraccionamiento o destilación primaria se realiza en la planta de Cabo Negro que procesa crudo a razón de $1.650 \mathrm{~m}^{3}$ por día. La Tabla $\mathrm{N}^{\circ} 3$ muestra el volumen de petróleo crudo procesado por estas distintas refinarías.

En el mercado de almacenamiento de productos derivados del petróleo, principalmente combustibles líquidos, la empresa dominante es la ex Empresa Almacenadora de Combustibles Ltda. (ex Emalco), filial de Enap, que almacena hidrocarburos tanto a empresas filiales de Enap como a terceros. Sin embargo, existen varias empresas que cuentan con almacenamiento propio como es el caso de Copec, Shell y 
TABLA N ${ }^{\circ}$ 3: $\quad$ PETRÓLEO CRUDO PROCESADO EN CHILE (M³)

(Años 2005 y 2006)

\begin{tabular}{|c|c|c|c|c|}
\hline \multirow[t]{2}{*}{ Refinería } & \multicolumn{2}{|c|}{ Nacional } & \multicolumn{2}{|c|}{ Importado } \\
\hline & 2005 & 2006 & 2005 & 2006 \\
\hline Aconcagua (ex RPC) & 133.867 & 52.227 & 5.620 .723 & 6.123 .389 \\
\hline Bío Bío (ex Petrox) & 79.417 & 110.323 & 5.614 .483 & 5.520 .322 \\
\hline Gregorio (Enap-Mag.) & & 0 & 701.058 & 779.130 \\
\hline Total & 213.283 & 162.550 & 11.936 .264 & 12.442 .840 \\
\hline
\end{tabular}

Fuente: SEC: Informe estadístico.

Esso. En total, la capacidad de almacenamiento en terminales de petróleo crudo, combustibles líquidos y gas licuado es de aproximadamente 3,3 millones de $\mathrm{m}^{3}$, total que se distribuye en 35\% a petróleo crudo, $7 \%$ a gas licuado y $58 \%$ a productos limpios y sucios.

Tal como se discute más adelante, el análisis del sector de almacenamiento de combustibles es clave desde el punto de vista de la organización industrial debido a la posibilidad de que las principales distribuidoras mayoristas ejerzan prácticas de exclusión de mercado a nuevos competidores y a la posibilidad de que Enap ejerza también algún tipo de poder de mercado.

En el Gráfico $N^{\circ} 3$ se presenta la estructura de propiedad de las plantas de almacenamiento de combustibles líquidos y petróleo, que suman aproximadamente 3 millones de $\mathrm{m}^{3}$. Se observa el predominio de parte de Enap, con un $72 \%$ correspondiendo a la ex Emalco, cuyas mayores plantas de almacenamiento se encuentran en sus tres refinerías.

Emalco S.A. nace en 1966, producto de la construcción del oleoducto entre la refinería de Talcahuano y la ciudad de San Fernando, con plantas en Linares y San Fernando. La propiedad de la empresa quedó constituida por un 98\% perteneciente a Enap, 1\% a Refinería de Petróleo Concón S.A. y el 1\% restante a Petrox S.A. Refinería de Petróleo (ambas propiedad de Enap).

Actualmente, ex Emalco S.A. es propietaria de tres plantas de almacenamiento en la zona central de Chile. Las plantas ubicadas en 
GRÁFICO N 3: PROPIEDAD DE LAS PLANTAS DE ALMACENAMIENTO (Año 2007)

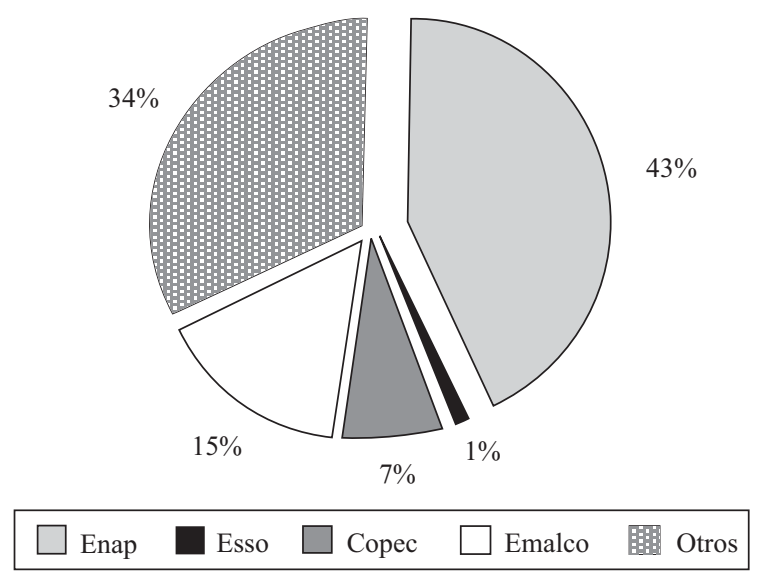

Fuente: Elaboración propia en base a datos de la SEC.

Maipú, San Fernando y Linares, cuentan con estanques de almacenamiento con una capacidad de $313.193 \mathrm{~m}^{3}$ para productos limpios y gas licuado, líneas de interconexión con estanques de terceros y/o con oleoductos, plantas de envasado de gas licuado e islas de carga de camiones.

La Tabla $\mathrm{N}^{\circ} 4$ muestra el volumen de salidas de los distintos terminales de ex Emalco hacia las distintas empresas para el año 2003, siendo sus principales clientes privados Repsol-YPF en combustibles líquidos y Abastible en gas licuado.

En la Tabla $\mathrm{N}^{0} 5$ se presenta la distribución geográfica de las plantas de almacenamiento, por empresa, para el año $2002^{3}$. Enap es líder en capacidad en las regiones donde opera, con un 80\% del total regional o más (salvo en la Región Metropolitana donde alcanza el 65\%). Le sigue en importancia Copec, en forma directa o a través de su filial Comap 4 , con una red de almacenamiento a lo largo de todo el

${ }^{3}$ En el año 2004, la capacidad total de almacenamiento era de $1.106 .378 \mathrm{~m}^{3}$ para petróleo crudo y $1.651 .354 \mathrm{~m}^{3}$ para combustibles líquidos, pero no hay información respecto a su distribución por empresa.

${ }^{4}$ Copec posee el $67 \%$ de sus acciones, en sociedad con Shell. A su vez, Copec, Esso y Shell participan por partes iguales en Siav. En la sección 2.4 se describe en más detalle las relaciones patrimoniales en la industria. 
TABLA N ${ }^{\circ}$ 4: $\quad$ SALIDAS DE TERMINALES DE EMALCO (Año 2003)

\begin{tabular}{lrrrr}
\hline & \multicolumn{4}{c}{ Terminal } \\
\cline { 2 - 5 } Empresas & Maipú & San Fernando & Linares & Total \\
& & & & \\
\hline Copec & 10.389 & 0 & 0 & 10.389 \\
CapdeVilla & 93.928 & 0 & 0 & 93.928 \\
Punto Blanco & 29.743 & 0 & 0 & 29.743 \\
Texaco & 5.986 & 0 & 1.024 & 7.010 \\
Repsol - YPF & 455.357 & 0 & 125.639 & 580.996 \\
Abastible & 237.881 & 69.623 & 13.832 & 321.336 \\
Codigas & 31.984 & 0 & 0 & 31.984 \\
Enagas & 0 & 37.841 & 3.151 & 40.992 \\
Gasco & 45.071 & 0 & 3.344 & 48.415 \\
RPC & 1.497 .108 & 0 & 0 & 1.497 .108 \\
Petrox & 395.806 & 258.970 & 0 & 654.776 \\
Total & & & & \\
& 2.803 .253 & 366.434 & 146.990 & 3.316 .677 \\
\hline
\end{tabular}

Nota: El volumen se expresa en $\mathrm{m}^{3}$ estándares $\left(15^{\circ} \mathrm{C}\right.$ o $\left.60^{\circ} \mathrm{F}\right)$.

Fuente: SEC.

TABLA N ${ }^{\circ}$ 5: $\quad$ CAPACIDAD DE ALMACENAMIENTO POR EMPRESA EN M ${ }^{3}$ (Año 2002)

\begin{tabular}{|c|c|c|c|c|c|c|}
\hline Región & Total & Enap & Сорес & Esso & Shell & Otras \\
\hline I & 98.914 & - & 57.474 & 36.504 & 4.936 & - \\
\hline II & 148.631 & - & 28.890 & 46.145 & 14.230 & 91.202 \\
\hline III & 50.673 & - & 22.681 & - & - & 27.992 \\
\hline IV & 33.156 & - & 16.327 & 16.829 & - & - \\
\hline V & 1.141 .967 & 968.995 & 34.323 & 33.075 & - & 105.574 \\
\hline $\mathrm{RM}$ & 277.172 & 178.000 & 43.161 & 29.571 & 22.540 & 3.900 \\
\hline VI & 67.549 & 54.000 & 9.078 & - & 4.471 & - \\
\hline VII & 21.600 & 21.600 & - & - & - & - \\
\hline VIII & 895.854 & 708.248 & 28.893 & 16.663 & 11.550 & 130.500 \\
\hline IX & 840 & - & - & - & - & 840 \\
\hline $\mathrm{X}$ & 26.204 & - & 10.975 & 9.823 & 5.406 & - \\
\hline XI & 8.179 & - & 4.349 & 1.915 & 1.915 & - \\
\hline XII & 279.483 & 274.898 & 3.072 & - & 1.513 & - \\
\hline Total & 3.082 .058 & 2.205 .741 & 259.224 & 190.525 & 66.560 & 360.008 \\
\hline
\end{tabular}

Fuente: Elaboración propia en base a datos de CNE y SEC. 
país y especial preponderancia en las regiones I (y XV), III, IV, X y XI. La compañía cuenta con doce plantas de almacenamiento, siendo propietaria de tres de ellas y vía Comap en las nueve restantes ${ }^{5}$. Cinco de estas plantas están conectadas permanentemente a través de oleoductos con las refinerías de Enap, principal proveedor de Copec. Las siete plantas restantes son abastecidas con productos nacionales e importados por vía marítima en buques tanque. Por otro lado, Esso tiene una distribución similar, mientras que la participación de Shell es minoritaria. Las otras empresas que poseen plantas de almacenamiento corresponden, en su mayoría, a empresas mineras o eléctricas.

En el mercado de transporte de combustibles derivados del petróleo, los productos refinados son transportados a los clientes mayoristas a través de oleoductos, barcos o camiones. Gran parte de los oleoductos son propiedad de Sonacol, cuyos ductos se concentran en el centro del país. En este caso, es de especial importancia la propiedad y uso de los oleoductos, ya que la estructura propietaria de esta empresa está compuesta por las principales compañías distribuidoras de combustibles líquidos, junto a Enap. Adicionalmente, la otra red de oleoductos, que conecta la refinería ex Petrox con la planta de almacenamiento en San Fernando, es de propiedad de Enap Refinerías S.A.

En la práctica, más del 70\% de los productos refinados destinados al mercado nacional se transportan a través de la red de oleoductos ubicada, principalmente, en la zona central del país. Esta red, sin considerar la existente en la zona de Magallanes, tiene una extensión total cercana a los $825 \mathrm{kms}$. De estos, $350 \mathrm{kms}$ corresponden al poliducto de Enap que une Talcahuano con San Fernando. A ello se agrega una amplia red de oleoductos, gasoductos y otras líneas en la zona de Magallanes, tanto en tierra como en costa afuera, que permiten la conducción de los productos a los centros de refinación y almacenamiento. En el resto del país el abastecimiento es efectuado por vía marítima.

La Tabla $\mathrm{N}^{\circ} 6$ muestra los volúmenes transportados por todos los oleoductos de la zona central en el año 2006.

La empresa Sonacol S.A., hasta hace muy poco, desarrollaba toda su actividad a través de dos unidades de negocios: Sonacol Oleo-

${ }^{5}$ Éstas se ubican en Arica, Iquique, Antofagasta, Caldera, Guayacán, Maipú, Las Salinas, San Fernando, Chillán, San Vicente, Puerto Montt y Puerto Chacabuco. 
TABLA N ${ }^{\circ}$ 6: $\quad$ TRANSPORTE DE COMBUSTIBLES POR OLEODUCTOS, EN MM M $^{3}$ (Año 2006)

\begin{tabular}{|c|c|c|c|c|c|}
\hline & GLP & Gasolina & Kerosene & $\begin{array}{r}\text { Petróleo } \\
\text { diésel }\end{array}$ & Total \\
\hline \multicolumn{6}{|l|}{ Concepción a: } \\
\hline Chillán & - & 267.303 & 2.159 & 588.925 & 858.387 \\
\hline Linares & 34.993 & 24.886 & 2.654 & 69.372 & 131.905 \\
\hline San Fernando & 67.723 & 139.721 & 74.318 & 215.497 & 497.259 \\
\hline Maipú & - & 3.162 & 53.325 & - & 56.487 \\
\hline \multicolumn{6}{|l|}{ San Fernando a: } \\
\hline Maipú & - & - & 110 & - & 110 \\
\hline \multicolumn{6}{|l|}{ Concón a: } \\
\hline Concón & 32 & 177 & - & 156 & 365 \\
\hline Maipú & 827 & 1.339 & 610 & 1.348 & 3.983 \\
\hline \multicolumn{6}{|l|}{ Maipú a: } \\
\hline Aeropuerto AMB & - & - & 615 & - & 615 \\
\hline Total & 103.576 & 436.589 & 133.791 & 875.298 & 1.549 .253 \\
\hline
\end{tabular}

Fuente: SEC: Informe estadístico.

ductos, propietaria y operadora de su red de tuberías; y Sonacol Marítima, armadora, administradora y operadora de buques dedicados al cabotaje y comercio exterior de combustibles, petróleo crudo y otros derivados. Sonacol S.A. es la empresa dominante en el mercado de transporte de combustibles derivados del petróleo, al transportar el 98\% de los combustibles a la Región Metropolitana.

La red de poliductos de Sonacol al año 2008 se muestra en la Tabla $N^{\circ} 7$. Ésta tiene una extensión total de 465 kilómetros y puede transportar poco más de 7,5 $\mathrm{Mm}^{3}$ anuales, siendo sus principales clientes en combustibles líquidos las refinerías de Enap y las empresas distribuidoras de combustibles Copec, Esso, Shell e YPF (actualmente Terpel).

La división Sonacol Marítima fue creada en el año 1979 con el fin de complementar la red de oleoductos de la zona central con servicios de transporte por mar hacia y desde los puntos más alejados del país. En el año 2005 se transformó en la Sociedad Nacional Marítima S.A. (Sonamar), sumando nuevos socios ligados al transporte marítimo en el año 2006. Esta empresa posee una flota de transporte petrolero que al año 
TABLA N ${ }^{\circ} 7: \quad$ POLIDUCTOS DE SONACOL S.A

(Año 2008)

\begin{tabular}{l} 
Poliducto \\
\hline Concón - Las Salinas \\
Quintero - Concón Línea 1 \\
Quintero - Concón Línea 2 \\
Concón - Maipú Línea 1 \\
Concón - Maipú Línea 2 \\
San Fernando - Maipú \\
Maipú - Aeropuerto
\end{tabular}

Longitud
10 kilómetros
21,5 kilómetros
23 kilómetros
134 kilómetros
134 kilómetros
135 kilómetros
17,5 kilómetros

Fuente: Sonacol S.A.

2008 supera los 220 mil DWT, compuesta por los buques tanques (capacidades de carga): Ancud (6.254 DWT), Abtao (9.145 DWT), Valdivia (66.745 DWT), Estrecho de Magallanes (68.157 DWT) y Papudo (64.896 DWT). Si bien la información en el mercado es que los principales clientes de Sonamar son Enap y Copec, no existen datos públicos sobre el volumen transportado a las distintas empresas, ni tampoco en qué terminales marítimos operan los distintos buques.

Adicionalmente a la capacidad de transporte de Sonalcol S.A. y Sonamar, las empresas distribuidoras cuentan con flotas de camiones tanques destinados a garantizar el abastecimiento de combustible a zonas alejadas de puertos y/o poliductos. Varias de ellas tienen dicha flota como parte de la empresa o bien tercerizan esta actividad, mientras otras como Copec la tiene en filiales especializadas.

Finalmente, según datos de la Comisión Nacional de Energía (CNE), existen 34 terminales marítimos relacionados con hidrocarburos distribuidos a lo largo de todo Chile, pero ubicados principalmente en las regiones no abastecidas por oleoductos (zonas norte y sur del país $)^{6}$. Lamentablemente, no hay datos disponibles acerca de la capacidad de almacenamiento y recepción de buques para cada uno de los terminales, lo que limita significativamente el análisis de este mercado.

${ }^{6}$ Hay 2 en Arica, 2 en Iquique, 1 en Mejillones, 4 en Antofagasta, 1 en Chañaral, 1 en Caldera, 2 en Huasco, 1 en Coquimbo, 1 en Isla de Pascua, 4 en Quintero, 3 en Valparaíso, 2 en San Vicente, 1 en Puerto Montt, 3 en Chacabuco, 1 en Punta Arenas, 2 en Punta Delgada, 2 en Tierra del Fuego y 1 en Puerto Williams. De estos terminales, 11 pertenecen a Enap, 5 a Copec, 4 a Esso, 1 a Comap (Copec y Shell), 1 Comaco (Esso y Shell) y el resto a otras empresas u organismos del Estado. 


\subsection{Actividades downstream: Distribución de combustibles líquidos}

En el mercado de distribución mayorista de combustibles líquidos participan un número pequeño de empresas privadas, las que comercializan tanto los derivados de petróleo refinados por Enap como los importados. La liberalización de la distribución mayorista en 1978 y la distribución minorista en 1982 buscó la entrada de nuevas empresas a la industria y una mayor competencia. Sin embargo, la estructura de los mercados de combustibles líquidos no ha cambiado significativamente desde entonces debido a que las empresas ya establecidas (Copec, Esso y Shell) siguen teniendo una participación de mercado, de manera directa, mayor al 90\%. Esto último se observa en la Tabla $\mathrm{N}^{0}$ 8, donde se presenta la participación por empresas en el mercado de combustibles líquidos a fines de 2003.

La Tabla $\mathrm{N}^{\circ} 9$ presenta el volumen de importaciones de combustibles líquidos para el año 2006. El 32,7\% del total de importaciones es realizado por compañías distribuidoras mayoristas, mientras Enap importa el 67,3\% restante. En gasolina la participación es más homogénea, pero en diésel Enap es el principal importador.

Esta mayor importación de Enap no es una constante en el mercado. Como se observa en la Tabla $N^{0} 10$, para los años 1998 a 2006 hay períodos, los cinco primeros de la muestra, en que las

TABLA N ${ }^{\circ}$ 8: $\quad$ PARTICIPACIÓN PORCENTUAL DE MERCADO DE DISTRIBUIDORAS (Año 2003)

Empresas

Directa Empresas de transporte Canal minorista Consumo interno

\begin{tabular}{lrrrr} 
Copec & 52,6 & 44,8 & 48,4 & 0,0 \\
YPF & 7,5 & 19,8 & 9,5 & 0,0 \\
Esso & 17,4 & 7,5 & 18,9 & 99,5 \\
Shell & 21,5 & 26,7 & 21,7 & 0,0 \\
Otras & 1,0 & 1,1 & 1,5 & 0,5 \\
Total & 100 & 100 & 100 & 100 \\
\hline
\end{tabular}

Nota:

Directa: Ventas a industriales, comercio o particulares.

Empresas de transporte: Ventas a empresas de transporte por calles y caminos.

Canal minorista: Ventas a estaciones de servicio y locales de venta al público general.

Consumo interno: Consumos propios de las empresas distribuidoras.

Fuente: Elaboración propia en base a informes de SEC. 
TABLA No 9: $\quad$ IMPORTACIONES DE COMBUSTIBLES LÍQUIDOS EN MM³ (Año 2006)

\begin{tabular}{lrr}
\hline \multirow{2}{*}{ Tipo de combustible } & \multicolumn{2}{c}{ Importaciones } \\
\cline { 2 - 3 } & Enap & Distribuidoras* \\
\hline Gas licuado & 613 & 705 \\
Gasolina & 400 & 341 \\
Kerosene & - & - \\
Kerosene aviación & 114 & - \\
Gasolina aviación & - & 537 \\
Petróleo diésel & 2.171 & 17 \\
Petróleo combustible & - & 1.600 \\
& 3.298 & $32,7 \%$ \\
Total & $67,3 \%$ & \\
\hline
\end{tabular}

*: Incluye importaciones directas de usuarios.

Fuente: SEC: Informe estadístico.

TABLA N N $^{\circ}$ 10: $\quad$ PARTICIPACIÓN EN LA IMPORTACIÓN DE COMBUSTIBLES LÍQUIDOS (Años 1998-2006)

\begin{tabular}{lccccccccc}
\hline Importaciones & 1998 & 1999 & 2000 & 2001 & 2002 & 2003 & 2004 & 2005 & 2006 \\
\hline & & & & & & & & & \\
\hline Enap & 34,2 & 32,5 & 50,0 & 39,9 & 35,8 & s/i & s/i & 62,8 & 67,3 \\
Distribuidoras & 65,8 & 67,5 & 50,0 & 60,1 & 64,2 & s/i & s/i & 37,2 & 32,7
\end{tabular}

Fuente: SEC: Informes estadísticos.

compañías distribuidoras realizaron las mayores importaciones de combustibles derivados líquidos.

Finalmente, la Tabla $\mathrm{N}^{\circ} 11$ entrega información de las ventas anuales de combustibles líquidos para cada tipo de canal de distribución utilizado en Chile en los años 2005 y 2006. Se aprecia que más del 95\% de la distribución de los combustibles refinados a los distintos tipos de usuarios es llevada a cabo por las distintas empresas privadas transportadoras de combustibles.

En el mercado de distribución minorista la venta a consumidor final se realiza a través de estaciones de servicio. Al año 2004, de las 
TABLA No 11: VENTAS ANUALES DE COMBUSTIBLES POR CANALES DE DISTRIBUCIÓN, $\mathrm{EN} \mathrm{M}^{3}$

(Años 2005 y 2006)

Tipo de combustible

\begin{tabular}{ccccc}
\multicolumn{3}{c}{ Ventas } & \multicolumn{2}{c}{ directas } \\
\hline \multicolumn{2}{c}{ Enap } & & & \multicolumn{2}{c}{ Compañías distribuidoras } \\
\cline { 5 - 6 } 2005 & 2006 & & 2005 & 2006
\end{tabular}

Gasolina 81

Gasolina 86

Gasolina 93 SP

Gasolina 95 SP

Gasolina 97 SP

Gasolina aviación

Kerosene aviación

Kerosene doméstico

Nafta liviana

P combustible 180

P combustible $\mathrm{N}^{\circ} 5$

P combustible $\mathrm{N}^{\circ} 6$

$P$ diésel

$P$ diésel A1

$P$ diésel A2

$\mathrm{P}$ diésel $\mathrm{B}$

$\mathrm{P}$ diésel Enap especial

$\mathrm{P}$ diésel invernal

Total

$\begin{array}{rrrr}- & - & - & 438 \\ - & - & - & - \\ 366 & 1.726 & 1.349 .867 & 1.351 .731 \\ - & - & 723.414 & 729.948 \\ - & - & 804.318 & 808.252 \\ - & - & 5.825 & 5.883 \\ 6.561 & 26.613 & 613.993 & 683.579 \\ 5 & 29 & 134.914 & 104.649 \\ 459.187 & 555.675 & 776.109 & 822.861 \\ - & - & 98.479 & 87.963 \\ 7.628 & 6.249 & 629.382 & 701.285 \\ - & - & 11.911 & 11.282 \\ - & - & 1.573 .805 & 1.452 .386 \\ - & - & - & - \\ 14.135 & 13.793 & 4.409 .097 & 4.665 .544 \\ & & & 32.549 \\ - & - & 44.828 & \\ 487.882 & 604.085 & 11.175 .938 & 12.062 .434\end{array}$

Fuente: SEC: Informes estadísticos.

1.483 bocas de expendio existentes para venta directa al público, un 42\% utilizaba bandera de Copec, constituyéndose en el actor principal en este mercado. Le sigue Shell con un 23\%, casi la mitad de Copec, y luego Esso con YPF en torno al 15\%. A nivel de distribución geográfica, la Región Metropolitana concentraba al año 2004 el 31\% de las estaciones de servicios del país.

Lamentablemente no existe información respecto a los volúmenes de combustibles vendidos a público por cada una de las distribuidoras minoristas (ni total ni por región).

Muchas de las estaciones de expendio de combustibles líquidos ofrecen servicios adicionales como minimercados, farmacias y/o caje- 
ros automáticos, utilizando marcas distintas para ello. Copec las marcas Pronto y Punto, Shell las marcas Shell Express Market, Esso las marcas On the Run y Tiger Market Express e YPF la marca Ampm.

\subsection{Relaciones patrimoniales de la industria}

Como se señaló anteriormente, en los mercados de extracción, producción y refinación de petróleo crudo Enap es el único actor, con algunos socios en proyectos puntuales. En el mercado de almacenamiento de combustibles líquidos, Enap participa a través de su ex filial Emalco S.A., mientras que las grandes distribuidoras mayoristas - Copec, Shell y Esso- participan en las almacenadoras Comaco y Comap. En la primera, tanto Shell como Esso tienen el 50\% de la propiedad, mientras que Copec posee el 67\% de la participación en la propiedad de Comap y el restante 33\% pertenece a Shell. En el mercado de transporte de combustibles líquidos, las tres mayores distribuidoras junto a Enap tiene participación en Sonacol S.A. Copec es el accionista mayoritario con una participación de 41\%, Esso y Enap tienen una participación de 22\% cada una y el 15\% restante pertenece a Shell. Mientras que en Sonamar participan Copec y Enap junto a las principales navieras de origen chileno: CSV y Ultramar. Un esquema de relaciones de propiedad que facilita entender los grados de integración vertical y horizontal existentes en la industria se presenta en la Figura $\mathrm{N}^{\circ}$ 2. Los mercados que tienen mayor relevancia en cuanto a las relaciones patrimoniales de los distintos actores de la industria son el de oleoductos y los de distribución.

El análisis de la estructura de propiedad de los oleoductos es importante porque es el medio de transporte más rápido y seguro para combustibles líquidos. El transporte de combustibles por camión es el sustituto más cercano, pero ciertamente más costoso; mientras que el transporte en barcos está bastante más acotado por las características propias de ese medio de transporte. La Tabla $\mathrm{N}^{0} 12$ presenta la estructura de propiedad de los oleoductos por tramo, el tipo de producto transportado y sus respectivas capacidades.

En el mercado de distribución de combustibles líquidos, tal como se mostró anteriormente, en 2003 Copec tenía la mayor participación en el mercado mayorista con un $48,4 \%$ en el canal minorista y 
FIGURA No 2: $\quad$ RELACIONES PATRIMONIALES DE EMPRESAS DE LA INDUSTRIA DEL PETRÓLEO

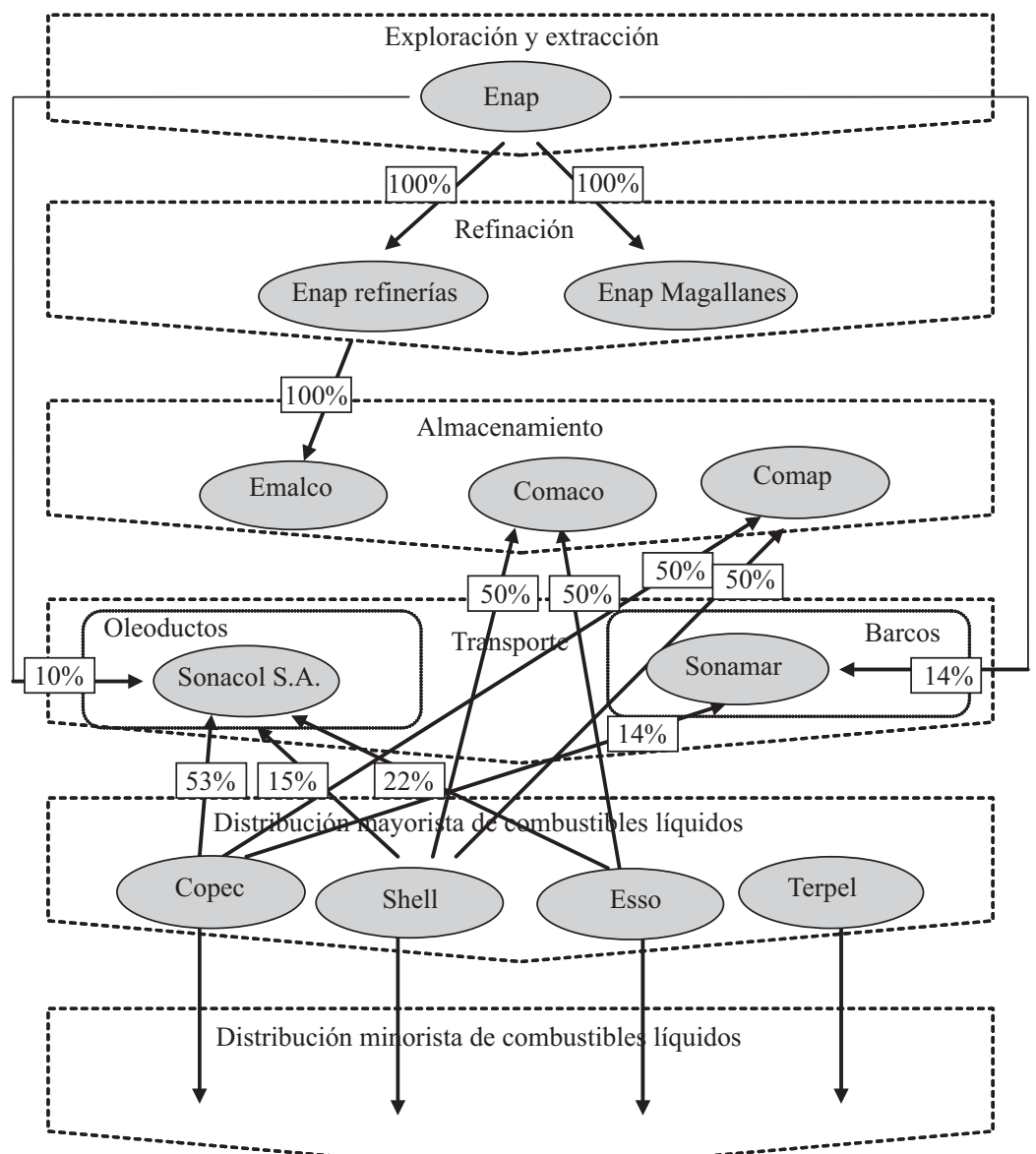

un $44,8 \%$ en el de empresas de transporte. De igual forma, $43 \%$ de las estaciones de servicio eran abastecidas por Copec en 2004, lo cual no debe ser muy diferente ahora y es probable que concentre aun una mayor cantidad de estaciones.

El análisis de los mercados de distribución mayorista y minorista de combustibles líquidos muestra que existe un alto grado de integración vertical entre ambos. Sin embargo, la propiedad de las estaciones de servicio no siempre es de las empresas distribuidoras mayoristas. De hecho existen en el mercado distintos tipos de relaciones contrac- 
TABLA No 12: $\quad$ OLEODUCTOS: PROPIEDAD, PRODUCTO Y CAPACIDAD (año 2004)

\begin{tabular}{|c|c|c|c|}
\hline & Propietario & Producto transportado & $\begin{array}{l}\text { Capacidad } \\
\text { bombeo }\left(\mathrm{m}^{3}\right)\end{array}$ \\
\hline Sica-Sica (Bolivia-Arica) & YPFB & Crudo y fuel oil & 199 \\
\hline Oleoducto Trasandino & OTS & Petróleo crudo & 750 \\
\hline Salinas - Concón & Sonacol & Combustibles líquidos & 240 \\
\hline Concón - Salinas & Sonacol & Fuel oil & 120 \\
\hline Concón - Maipú 1 & Sonacol & GLP & 437 \\
\hline Concón - Maipú 2 & Sonacol & Combustibles líquidos & 570 \\
\hline Maipú - Maipú (1) & Sonacol & GLP y comb. líquidos & 150 \\
\hline Maipú - Aeropuerto & Sonacol & Kerosene de aviación & 110 \\
\hline San Fernando - Maipú & Sonacol & Combustibles líquidos & 71 \\
\hline San Fernando - San Fernando & Enap & Combustibles líquidos & 130 \\
\hline San Vicente - San Vicente & Enap & Combustibles líquidos & s $\quad 1080$ \\
\hline San Vicente - San Vicente F.O. & Enap & Fuel oil & 1200 \\
\hline San Vicente - Bulnes & Enap & Comb. líquidos y GLP & 270 \\
\hline Bulnes - San Fernando & Enap & Comb. líquidos y GLP & 185 \\
\hline San Vicente - Maipú & Sonacol/Enap & Combustibles líquidos & 140 \\
\hline San Vicente - San Fernando & Sonacol & Combustibles líquidos & 170 \\
\hline San Vicente - Linares & Enap & Combustibles líquidos & 200 \\
\hline San Vicente - Chillán & Enap & Combustibles líquidos & 240 \\
\hline Estenssoro - Pedrals (2) & YPF/Enap & Petróleo crudo & 750 \\
\hline Bandurria (3) & Enap Magallanes & Propano/butano & 25 \\
\hline Cullen - Percy & Enap Magallanes & Combustible líquidos & 32 \\
\hline Percy - Cabo Negro & Enap Magallanes & Combustible líquidos & 32 \\
\hline Posesión - Cabo Negro & Enap Magallanes & Combustible líquidos & 63 \\
\hline Cabo Negro - Gregorio & Enap & Gasolina & 30 \\
\hline Gasolinoducto & Enap Magallanes & Gasolina & 30 \\
\hline Cullen - Clarencia & Enap Magallanes & Petróleo crudo & 79 \\
\hline B.R.C. - Planta Cullen & Enap Magallanes & Petróleo crudo & 104 \\
\hline Flamenco - Cullen & Enap Magallanes & Petróleo crudo & 33 \\
\hline Victoria Sur - Estancia Nueva & Enap Magallanes & Petróleo crudo & 33 \\
\hline Daniel - Gregorio & Enap Magallanes & Petróleo crudo & 146 \\
\hline Dungeness - Daniel & Enap Magallanes & Petróleo crudo & 50 \\
\hline
\end{tabular}

Notas: (1) Desde almacenamiento a compañías; (2) Neuquén a Talcahuano (3) Frontera a Planta Cullen.

Fuente: Comisión Nacional de Energía (CNE).

tuales entre quién abastece como mayorista y quién distribuye a público. El tipo de contrato depende de dos variables fundamentales: la propiedad (del terreno, principalmente) y la operación de la estación de servicio.

Un primer tipo de contrato consiste en que los distribuidores minoristas tengan sus propias empresas independientes y sean dueños de los terrenos donde operan las estaciones de servicio. A través de un comodato, el distribuidor mayorista les permite utilizar los estanques y 
surtidores que son de su propiedad y les suministra combustible. Si el minorista no cumple con determinadas exigencias, se ve obligado a arrendar los terrenos al distribuidor. Un segundo tipo de contrato ocurre cuando las distribuidoras realizan la instalación de estaciones de servicio de su propiedad y luego las arriendan a minoristas. En este caso se establece un contrato de distribución entre ambas empresas o se constituyen sociedades comerciales subsidiarias que explotan, por cuenta de las compañías distribuidoras, las estaciones de servicio. Finalmente, existen contratos en que la compañía distribuidora es arrendataria de la estación de servicio y la subarrienda al operador, quien revende el combustible. Ciertamente, dentro de estos contratos hay diversas variantes menores.

En el año 1991 el 17\% de las estaciones de servicio eran operadas por empresarios independientes de los distribuidores mayoristas y dueños de la estación, el $41 \%$ por arrendatarios de los distribuidores y otro $41 \%$ por comisionistas de esas empresas (Fuentes, Paredes y Vatter, 1994). Durante todos los años 90 hubo una fuerte tendencia a aumentar el grado de concentración en el segmento de distribución mayorista, con un efecto importante en el segmento de distribución minorista. De hecho, de acuerdo a información de la CNE para el año 2002, el 53\% de las estaciones de servicio eran de propiedad o usufructo de las propias empresas distribuidoras, sus relacionadas o filiales. Así, a través de distintas modalidades contractuales, en diez años se produjo una fuerte integración vertical en estos mercados, pasando desde un modelo de distribución regido principalmente por relaciones contractuales con terceros a un modelo de distribución con mayor integración vertical y operación vía empresas filiales.

\section{EVOLUCIÓN DE LA POLÍTICA DE PRECIOS}

En un análisis de la industria de combustibles líquidos, un aspecto central a considerar se refiere al grado de influencia que cada agente económico pueda tener sobre el precio, ya que la existencia de poder de mercado por parte de alguno de ellos generaría una pérdida en la eficiencia asignativa de la economía. Para realizar dicho análisis se requiere, en primer lugar, entender cuál es la estructura de precios de los combustibles líquidos y cómo se determina. 
Dado que Chile es un país fundamentalmente importador y existe libertad para importar y producir, los precios que determina Enap tanto para el petróleo crudo como para sus productos derivados se rigen por los precios de las importaciones. Los precios de paridad de importación (PPI) se determinan usando como referencia el valor de los diferentes combustibles en el mercado de la costa de Estados Unidos en el Golfo de México ${ }^{7}$, al cual se le suman los costos de flete y seguros a puertos chilenos, los derechos de aduana y gastos de internación, los costos de logística y el margen del importador. A modo de ejemplo, se presenta en la Tabla $\mathrm{N}^{0} 13$ como Enap determina el PPI para los productos derivados del petróleo, en este caso gasolina 93 octanos $^{8}$.

Es así como para el petróleo crudo producido en el país por Enap-Magallanes, el precio se determina a partir del precio de paridad de crudos importados equivalentes al nacional, valor al cual Enap vende el crudo que produce a sus propias refinerías.

TABLA N ${ }^{\circ} 13$ :

PRECIO PARIDAD DE IMPORTACIÓN PARA GASOLINA DE 93 OCTANOS EN US\$ ( $3^{\text {a }}$ semana de mayo de 1999)

Concepto

$\mathrm{US} \$ / \mathrm{m}^{3}$

Precio mercado referencia (US Coast Gulf)

130,8

Seguro y fletes (a puertos chilenos)

15,5

Derechos Aduana

14,6

Gastos internación

1,1

Logística (terminal y almacenamiento)

3,6

Margen importador

6, 6

Paridad importación

172,2

Fuente: Enap: "Política de Precios y Fondo de Estabilización de Precios del Petróleo”, marzo 2000.

\footnotetext{
${ }^{7}$ Este mercado concentra cerca de 50\% de la capacidad de refinación de Estados Unidos y está compuesto por las refinerías, oleoductos, terminales marítimos y plantas de almacenamiento ubicados en las costas de Alabama, Louisiana, Mississippi y Texas en el Golfo de México.

${ }^{8}$ Lamentablemente no existe información pública con posterioridad a mayo de 1999 respecto a los valores detallados que conforman el precio de paridad de información.
} 
TABLA N ${ }^{\circ} 14: \quad$ PRECIOS ENAP A DISTRIBUIDORES MAYORISTAS EN SANTIAGO

(\% del precio de venta al 30 de octubre de 2008)

\begin{tabular}{lrr}
\hline & Gasolinas & Diésel \\
\hline & & \\
PPI en Concón & $58,2 \%$ & $67,6 \%$ \\
Oleoducto Concón-Maipú & $0,9 \%$ & $1,0 \%$ \\
FEPP & $8,1 \%$ & $7,4 \%$ \\
Impuesto específico & $20,0 \%$ & $9,6 \%$ \\
IVA & $12,8 \%$ & $14,4 \%$ \\
Precio venta mayoristas & $100 \%$ & $100 \%$ \\
\hline
\end{tabular}

Fuente: ENAP.

En forma similar, el precio de los productos derivados del petróleo a los cuales vende Enap a los distribuidores mayoristas se determina a partir del PPI al cual se le suman las tarifas correspondientes al transporte (oleoductos) y almacenamiento, los efectos del Fondo de Estabilización de Precios de Combustibles (Fepc), el IVA y los impuestos específicos. En la Tabla $\mathrm{N}^{\circ} 14$ se muestra la composición porcentual de los precios de Enap a distribuidores mayoristas en Santiago.

Finalmente, los distribuidores determinan libremente, a partir del precio al cual compraron a Enap y su margen de comercialización, los precios finales a consumidores. En la composición de este precio es importante analizar con mayor detalle el rol que juegan cada uno de sus componentes, especialmente el de los costos de transporte y almacenamiento, los impuestos específicos a los combustibles, el Fondo de Estabilización de Precios y los márgenes de comercialización.

\section{Impuestos específicos}

Desde abril de 1986 (Ley 18.502) se aplica un impuesto específico, por metro cúbico, a las gasolinas automotrices y al diésel utilizado para el transporte en carreteras. El Gráfico $\mathrm{N}^{\circ} 4$ muestra la evolución que ha tenido la tasa del impuesto en el tiempo. En 1990 el impuesto era de 3.4893 UTM, se aumentó a 3.6186 UTM en 1991, a 4.4084 UTM en 1995, a 5,2 UTM en 2000, 6 UTM en 2001 y luego se disminuyó a 4,5 UTM en marzo de 2008 y finalmente a 3,5 UTM en septiembre de 2008. Durante todo este período, el impuesto al diésel se ha mantenido en 1,5 UTM por metro cúbico. 


\section{GRÁFICO No ${ }^{\circ}$ : $\quad$ EVOLUCIÓN IMPUESTO A LOS COMBUSTIBLES}

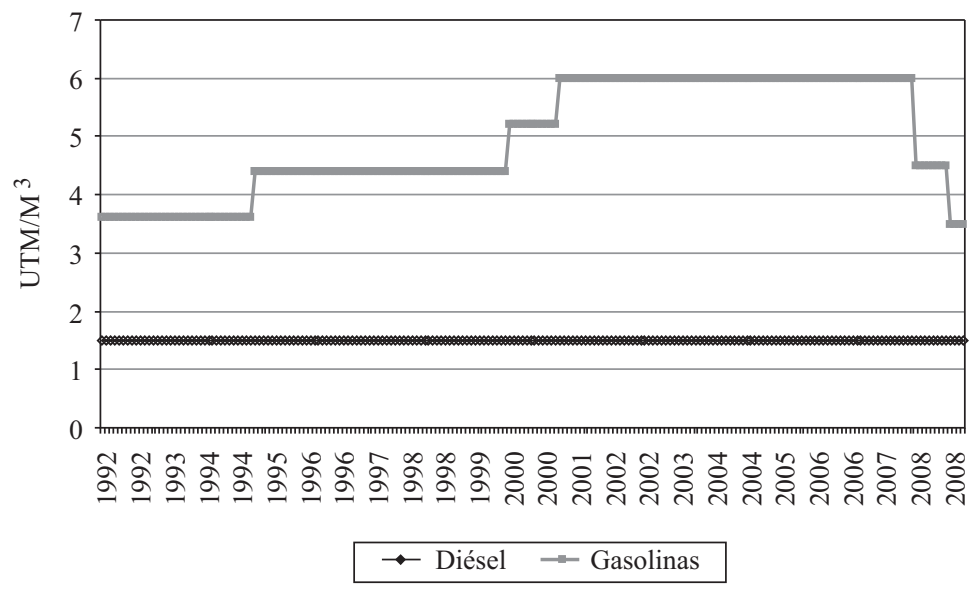

Fuente: Elaboración propia.

Uno de las preguntas principales respecto a los impuestos específicos, y para la cual no hay evidencia empírica en Chile que permita responderla, se refiere a qué fracción del impuesto se traspasa a precios finales a consumidores. En un mercado con competencia perfecta, el traspaso de un impuesto específico a precios depende exclusivamente de las elasticidades relativas de la oferta y la demanda en el mercado ${ }^{9}$. En los casos particulares en que la oferta es completamente elástica o la demanda es completamente inelástica, el impuesto se traspasa $100 \%$ a precios finales a consumidores. Por ello es que se considera que en el corto plazo la incidencia del impuesto recae tanto en consumidores como en productores y, en el largo plazo, cuando los factores de producción son todos variables y la curva de oferta es completamente elástica, recae completamente en los consumidores.

Por otro lado, en mercados con competencia imperfecta, la incidencia de un impuesto no recae $100 \%$ en los consumidores en el largo plazo y la tasa de traspaso del impuesto a precios finales de consumidores es mayor o menor al 100\% del impuesto (Katz y Rosen (1985), Stern (1987), Delipalla y O’Donell (2001)). Incluso en los casos en los cuales los bienes que compran los distribuidores son

${ }^{9}$ La incidencia de un impuesto específico se puede aproximar por $(\eta /(\eta-\varepsilon))$, donde $\eta$ es la elasticidad de la demanda en el mercado y $\varepsilon$ la elasticidad de la oferta. 
transados en mercados competitivos es posible que el mercado de distribución sea imperfectamente competitivo y la tasa de traspaso tributario sea mayor a uno (Hall, 1988).

La evidencia empírica internacional del traspaso de los impuestos a los combustibles a precios finales es relativamente escasa y con resultados mezclados. El trabajo de Chouinard y Perloff (2004) muestra una tasa de traspaso a consumidores del orden de $50 \%$ en el impuesto específico federal en Estados Unidos y una tasa de 100\% en los impuestos específicos estatales. El trabajo de Alm, Sennoga y Skidmore (2008), usando datos mensuales para cincuenta estados en Estados Unidos durante el período 1984-1999, muestra una tasa de traspaso de $100 \%$ del impuesto a los combustibles en las zonas urbanas y menor a $100 \%$ en las zonas rurales. Finalmente, Doyle y Samphantharak (2008) estudian el efecto que tuvo la suspensión temporal del impuesto a la venta de gasolinas en el año 2000 durante 4 meses en Indiana y seis meses en Illinois. Utilizando datos desagregados a nivel de estaciones de servicio muestran que los precios de la gasolina disminuyeron 3\% cuando el impuesto de $5 \%$ se redujo a $0 \%$ y luego subieron $4 \%$ cuando se volvió a aplicar el impuesto de 5\%, lo cual implica una tasa de traspaso tributario entre $60 \%$ y $80 \%$.

Lamentablemente, no existe evidencia empírica para Chile respecto al traspaso tributario a precios. Lo más cercano es el trabajo de Balmaceda y Soruco (2008) que estudia el traspaso del precio internacional del petróleo a precios finales a consumidores, encontrando evidencia de asimetría en dicho traspaso al efectuarse más rápidamente y con mayor magnitud cuando el precio sube respecto a cuando el precio baja.

\section{Transporte y almacenamiento}

La tarifa de transporte por oleoducto es fijada por la empresa Sonacol y la tarifa por almacenamiento por ex Emalco. Si bien ambas empresas tienen el poder de fijación de las respectivas tarifas, éstas tienen como límite superior los precios del transporte carretero por camiones y los precios de almacenamiento propio que poseen las compañías distribuidoras mayoristas respectivamente (como se vio en la sección 2.4, Shell, Esso y Copec tienen participaciones en sus propias empresas de almacenamiento). En este sentido el poder de mercado 
máximo que podría ejercer Sonacol sería el de fijar las tarifas utilizando como precio límite el precio del transporte de combustible en camiones, por lo que la pregunta relevante es cuál es la magnitud de ese precio límite respecto al precio competitivo.

\section{Fondo de estabilización}

Con el objetivo de suavizar las fluctuaciones de precios de venta de los combustibles derivados del petróleo producto de las variaciones del precio internacional del petróleo, se estableció una política de estabilización de precios a través de la creación en 1991 (ley N 19.030) del Fondo de Estabilización de Precios del Petróleo (Fepp). Los combustibles para los cuales opera el Fepp son las gasolinas automotrices, el kerosene doméstico, el petróleo diésel, los petróleos combustibles ( $N^{\circ} 5, N^{\circ} 6$ e IFO) y el gas licuado (propano, butano, mezcla propanobutano y gas licuado de petróleo para combustión catalítica).

El Fepp opera a partir de dos tipos de precios. El primero es un precio de referencia intermedio, determinado por el Ministerio de Minería previo informe de la $\mathrm{CNE}$, que corresponde al precio esperado a mediano y largo plazo del mercado petrolero. A partir de este precio de referencia se calcula un precio de referencia superior y uno inferior, que no pueden diferir en menos de un 12,5\% del precio de referencia intermedio, que determinan una banda de precios. El segundo es un precio de paridad de importación, determinado por la CNE, que corresponde al precio promedio semanal de las cotizaciones en los mercados internacionales (incluyendo costo de transporte y seguros).

El Precio de Referencia Intermedio (PRI), sobre el cual se construye la banda de precios, se calculaba de la siguiente manera:

$\mathrm{PRI}=$ 0,4 p. histórico + 0,25 p. proyectado ${ }_{\text {corto plazo }}+$ 0,35 p. proyectado largo plazo

El precio histórico es un promedio ponderado de los últimos cuatro valores medios semestrales de precios de paridad, anteriores a la semana para la cual se calcula el PRI. El precio proyectado de corto plazo se construye sobre la base de predicciones semanales de precios de los combustibles; y el precio proyectado de largo plazo consiste en un promedio simple de las proyecciones de precios de paridad promedios anuales para los siguientes diez años. 
El mecanismo de estabilización utilizado a través del Fepp consiste, por un lado, en que cada vez que el precio de paridad de un combustible es menor al precio de referencia inferior, se cobra un impuesto equivalente al $60 \%$ de la diferencia entre ambos. Por otro lado, cada vez que el precio de paridad de importación está sobre el precio de referencia superior, se establece un crédito equivalente a $100 \%$ de la diferencia entre este precio y su paridad observada. Cuando el precio se encuentra dentro de la banda determinada por los precios de referencia el Fepp no opera.

De esta forma, el Fepp recibía recursos del fisco cuando el precio de paridad de un combustible era menor al precio de referencia inferior y el fisco retiraba recursos del Fepp cuando el precio de paridad de un combustible era mayor al precio de referencia superior. El Gráfico $\mathrm{N}^{\circ} 5 \mathrm{~A}$ muestra la evolución de los precios de referencia y paridad de las gasolinas desde la creación del Fepp hasta su modificación a mediados del 2000.

En julio de 2000 se introdujeron modificaciones importantes al funcionamiento del Fepp (ley 19.681). Se estableció la banda de precios como $12,5 \%$ respecto al precio de referencia intermedio y, adicionalmente, que este último no podía diferir en más de $20 \%$ del promedio de precios de paridad observados en el año móvil anterior a la semana para la cual se determina el PRI.

Si el precio de referencia inferior (PRinf) es mayor que el precio de paridad $\left(\mathrm{P}^{*}\right)$, el producto estará gravado por un impuesto cuyo monto por metro cúbico, vendido o importado, según corresponda, será igual a:

$$
T_{\text {FEPP }}=\left(P R_{\mathrm{inf}}-P^{*}\right) \text { Min. }\left(1, \frac{F^{*}-F}{q\left(P R_{\mathrm{inf}}-P^{*}\right) t}\right)
$$

donde $\mathrm{F}^{*}$ es el fondo objetivo, $\mathrm{F}$ el fondo disponible, q la cantidad de consumo semanal promedio esperado de las próximas doce semanas y t el parámetro de protección temporal.

Si el precio de paridad $\left(\mathrm{P}^{*}\right)$ excede el precio de referencia superior (PRsup), operará un crédito fiscal, por metro cúbico, vendido o importado, según corresponda, será igual a:

$$
C_{\text {FEPP }}=\left(P^{*}-P_{\text {sup }}\right) \text { Min. }\left(1, \frac{F}{q\left(P^{*}-P_{\text {sup }}\right) t}\right)
$$


GRÁFICO N ${ }^{\circ}$ 5A: PRECIOS DE PARIDAD Y REFERENCIA GASOLINAS CON FEPP

(Ley 19.030)

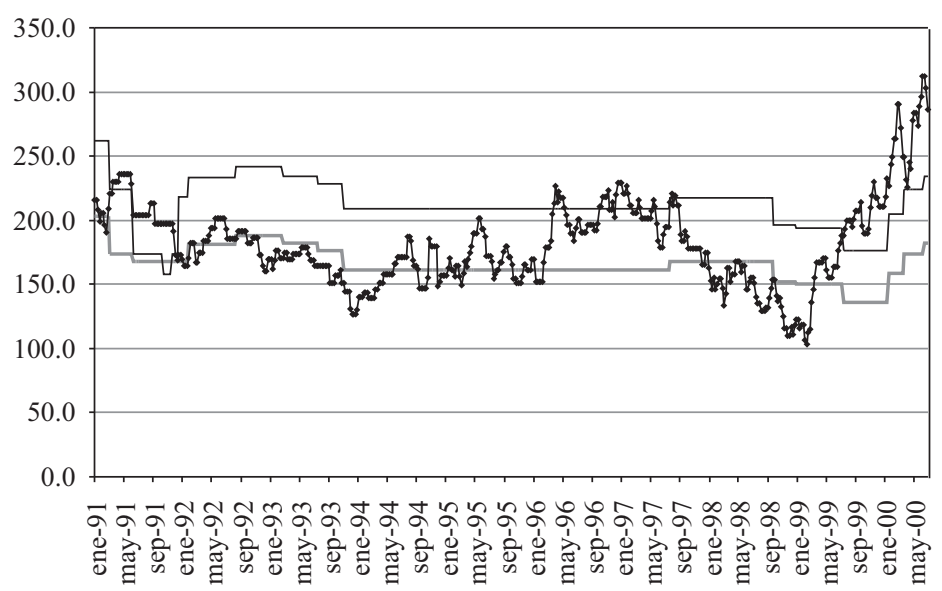

\section{- Precio inferior - Precio superior $\rightarrow$ Precio paridad}

Fuente: Elaboración propia en base a informes estadísticos de la Comisión Nacional de Energía (CNE).

GRÁFICO N 5B: PRECIOS DE PARIDAD Y REFERENCIA GASOLINAS CON FEPP (Ley 19..681)

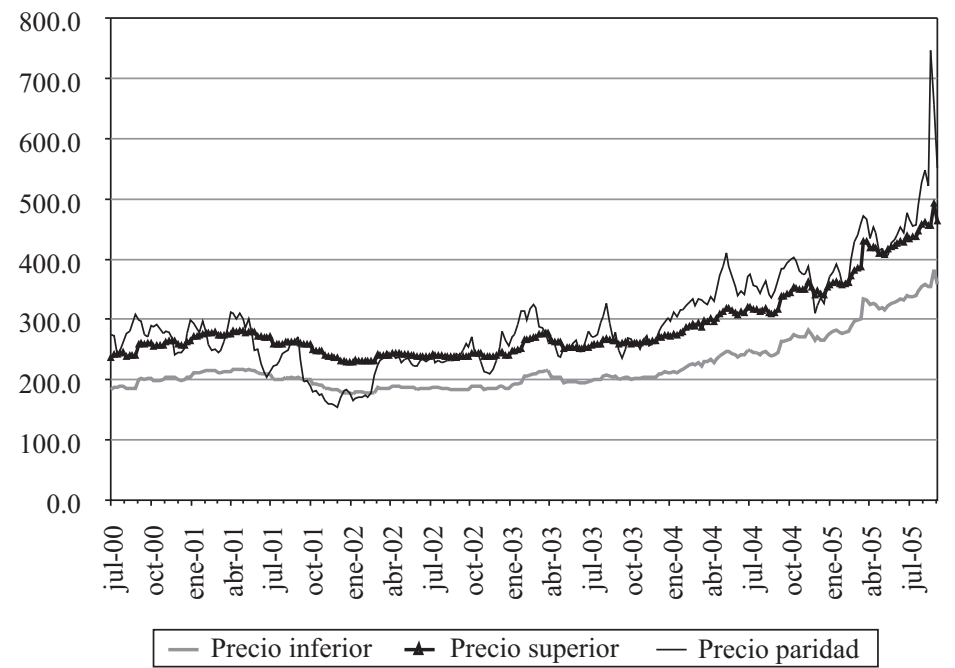

Fuente: Elaboración propia en base a informes estadísticos de la Comisión Nacional de Energía (CNE). 


\section{GRÁFICO N 6: $\quad$ FONDO DE ESTABILIZACIÓN DE PRECIOS DEL PETRÓLEO}

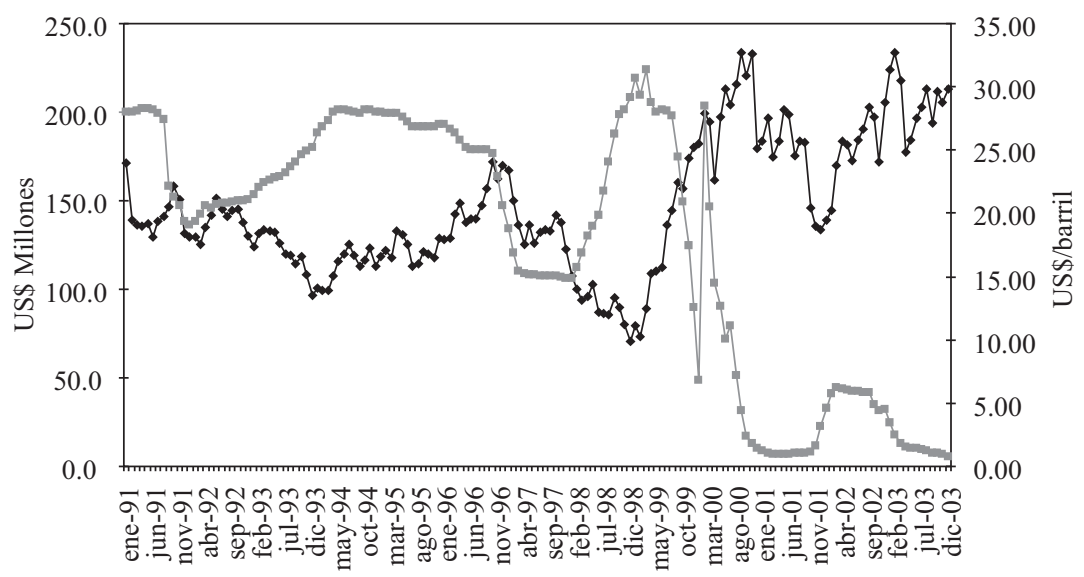

\section{$\rightarrow$ Saldo Fepp $\rightarrow$ Precio petróleo}

Fuente: Elaboración propia en base a informes estadísticos de la Comisión Nacional de Energía (CNE).

GRÁFICO N ${ }^{\circ}$ 7: $\quad$ PRECIOS PARIDAD Y REFERENCIA GASOLINAS CON FEPC (Leyes 20.063, 20.115 y 20.197)

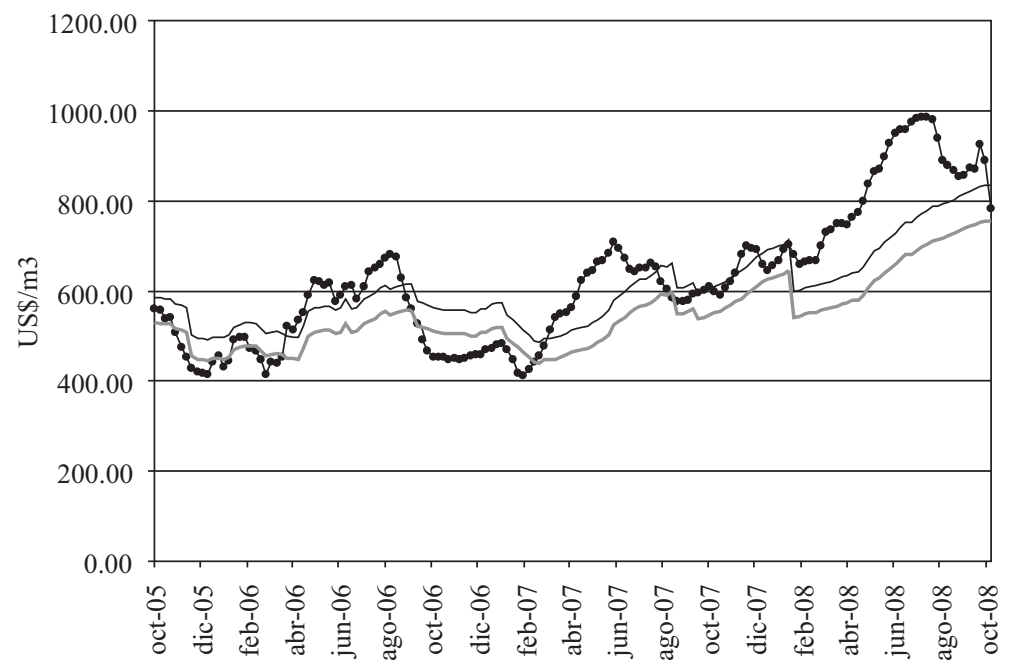

\section{Precio paridad - Precio inferior - Precio superior}

Fuente: Elaboración propia en base a informes estadísticos de la Comisión Nacional de Energía (CNE). 
El Gráfico No 5B muestra la evolución de los precios de referencia y paridad de las gasolinas desde julio del 2000 hasta agosto de 2005. Asimismo, el Gráfico No 6 muestra la evolución de los recursos del Fepp desde su creación hasta diciembre de 2003.

Finalmente, en octubre de 2005 comienza a operar el Fondo de Estabilización de Precios de Combustibles Derivados del Petróleo (Fepc), con el objetivo de reducir las fluctuaciones en los precios de la gasolina automotriz, el petróleo diésel y el kerosene doméstico, dejándole al Fepp el rol de estabilizar los precios del petróleo combustible y el gas licuado. El Gráfico No 7 muestra la evolución de los precios de referencia y paridad desde que entró en funcionamiento el Fepc.

\section{Margen de comercialización}

El margen de comercialización (distribución minorista) depende fundamentalmente del grado de competencia en cada uno de los mercados geográficos en que participan los distribuidores. En los Gráficos $\mathrm{N}^{\text {os }} 8 \mathrm{~A}, 8 \mathrm{~B}$ y $8 \mathrm{C}$ se muestran el margen de comercialización y los precios reales para distintos combustibles líquidos para la Región Metropolitana, mensuales desde enero de 2004 hasta septiembre de 2008. El margen de comercialización es calculado por la CNE como la diferencia entre el precio promedio de venta al público y el Fepp, impuesto específico, IVA y precio en refinería. El precio promedio de venta al público se obtiene a través de encuestas en las estaciones de servicios realizadas por Sernac (Servicio Nacional al Consumidor).

La comparación entre los márgenes de comercialización para los distintos combustibles muestra sistemáticamente un margen mayor para el kerosene doméstico respecto a la gasolina y el petróleo diésel, lo cual puede ser signo de un mercado menos competitivo.

Los Gráficos Nos 9A, 9B y 9C muestran los márgenes de comercialización, calculados como porcentajes sobre el precio final a consumidores, para el período enero 2004-diciembre 2007 en las regiones para las cuales la CNE provee de información.

En la V y VIII Región se observan los mayores márgenes para los distintos tipos de combustibles, mientras que en la XII y Región Metropolitana se encuentran los menores. Esto es consistente con la existencia de competencia espacial en el mercado minorista, lo cual hace que un mayor número de estaciones de servicio disminuya los precios. 


\section{GRÁFICO N 8: $\quad$ MARGEN DE COMERCIALIZACIÓN Y PRECIOS REALES EN LA RM}

GRÁFICO 8A: GASOLINA

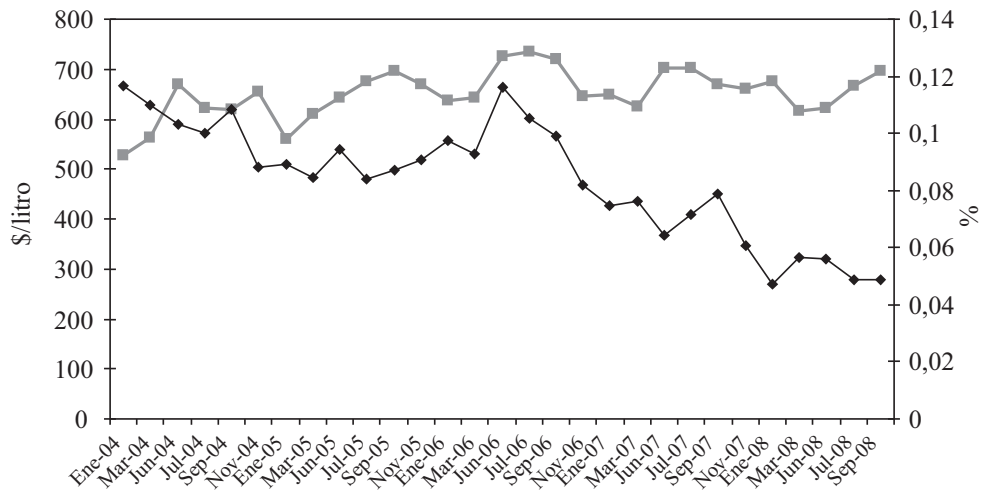

GRÁFICO 8B: KEROSENE

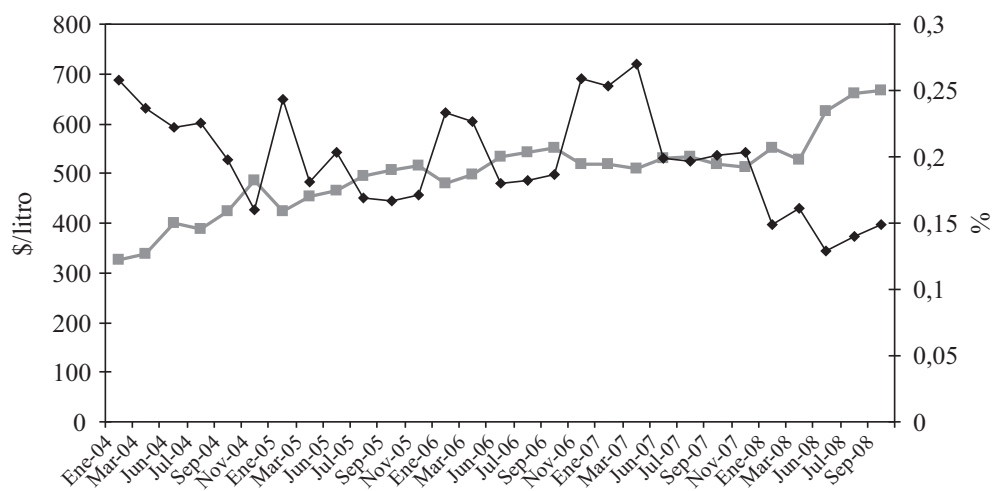

GRÁFICO 8C: DIÉSEL

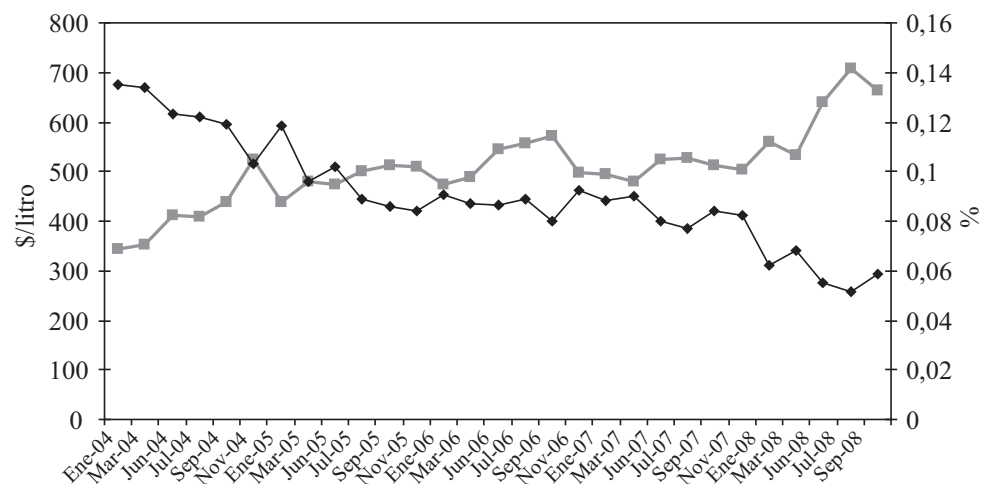

Fuente: CNE. 
GRÁFICO N 9: MARGEN DE COMERCIALIZACIÓN (\% DE PRECIO FINAL)
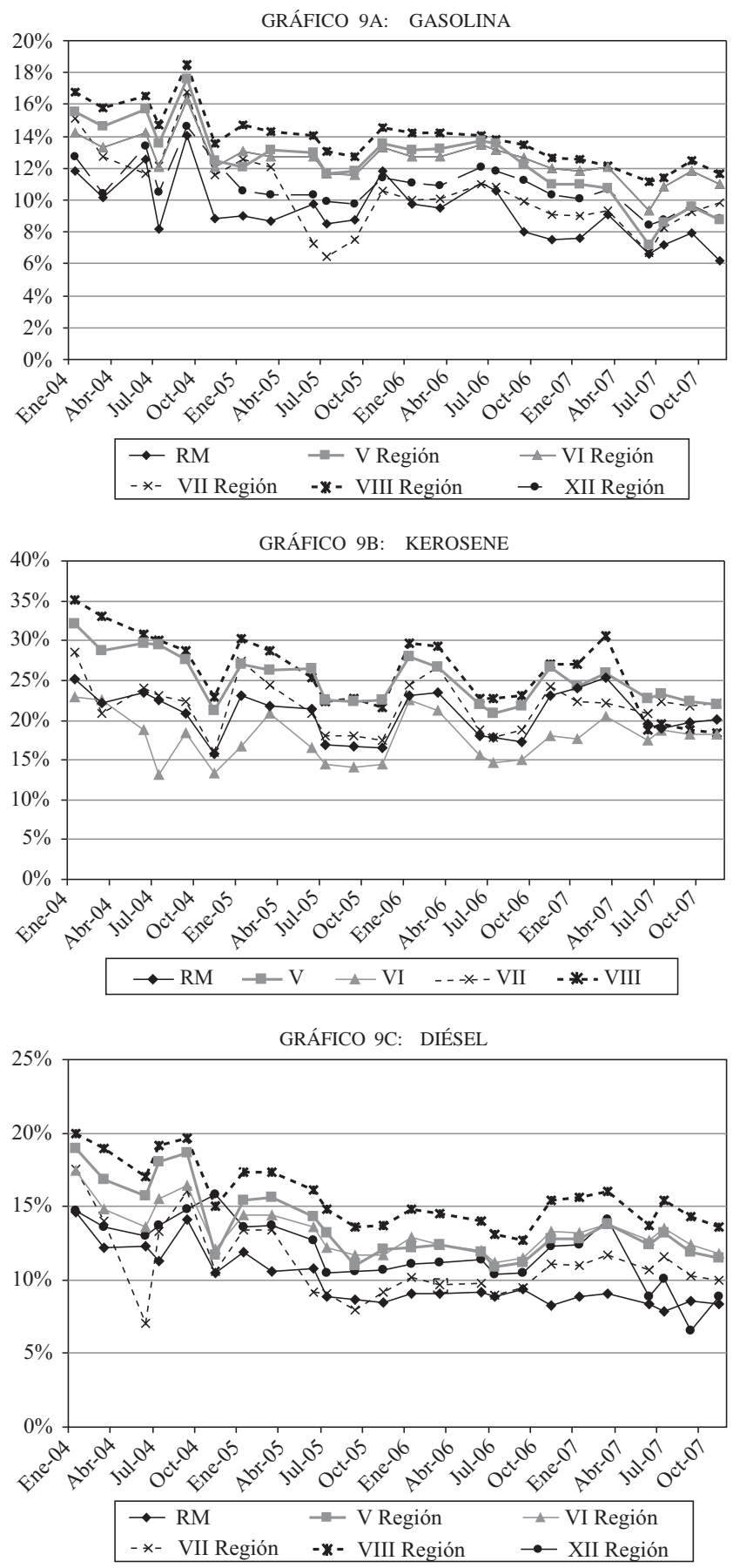

Fuente: CNE. 


\section{ORGANIZACIÓN INDUSTRIAL DEL SECTOR}

Una mirada de organización industrial a la industria del petróleo y sus derivados líquidos es de interés no sólo académico sino también, y principalmente, de política pública, ya que permite identificar las barreras a la entrada en estos mercados y la potencial influencia sobre el precio de los productos de cada uno de los agentes económicos en cada mercado relevante.

En general, y al igual que en la mayor parte del mundo, la industria del petróleo y sus derivados tiene un alto grado de concentración en cada mercado relevante y existe también un grado importante de integración vertical entre ellos. Respecto del grado de concentración, siempre es importante señalar en primer lugar que la existencia de un grupo reducido de firmas (o en el caso extremo de un monopolio) no necesariamente indica a priori una falta de competencia en ese mercado. Lo importante es establecer la existencia o inexistencia de barreras a la entrada en el mercado relevante y el grado de sustituibilidad que tienen otros productos disponibles en otros mercados.

Respecto a la integración vertical, es importante señalar que ésta puede generar economías de ámbito importantes que permiten una mejor eficiencia productiva de la industria. Sin embargo, también pueden generar barreras a la entrada que reduzcan considerablemente el grado de competencia en algunos mercados. Por ello, es especialmente importante considerar el potencial uso de controles verticales que permitan extraer rentas en los mercados más competitivos de la industria, generando así ineficiencias en la asignación de los recursos. De igual forma, se requiere asegurar la entrada potencial de nuevas firmas en todos los mercados relevantes de la industria para evitar el abuso de posición monopólica de aquellas firmas que operan en los mercados menos competitivos de la industria.

Finalmente, un aspecto relacionado e importante de considerar es la posibilidad de eventuales alianzas de negocios entre uno o dos actores importantes en la industria, con el objeto de excluir del mercado a otros competidores.

A continuación, con el objetivo de facilitar el análisis de la organización industrial de la industria, se considera por separado cada mercado relevante y luego las relaciones e impactos entre cada uno de ellos. 


\subsection{Mercados upstream}

En primer lugar, es importante recordar para el análisis de este mercado que la ley establece que todos los yacimientos petrolíferos que se encuentren en el territorio nacional son de propiedad del Estado. Tal como se señaló previamente, Enap tuvo el monopolio legal de la exploración y explotación de petróleo en Chile. Sin embargo, desde 1975 el Estado puede ejercer la facultad de explotar los yacimientos petrolíferos no sólo a través de Enap directamente, sino que también a través de concesiones administrativas a terceros o bien mediante contratos especiales de operación petrolera (Ceop). Como resultado de este cambio en las condiciones del mercado de prospección y exploración, a partir de 1977 se produjo el ingreso de empresas privadas a la exploración en asociación con Enap.

El hecho de que el Estado sea el dueño de los yacimientos petrolíferos y pueda libremente decidir si opera directamente a través de Enap o si permite la participación de privados a través de concesiones o Ceop, constituye sin duda una potencial barrera a la entrada en el mercado de exploración y explotación de petróleo. Si bien la existencia de Ceop muestra que la entrada a este mercado no ha sido completamente bloqueada por parte del Estado, llama la atención el hecho de que Enap haya participado en todos los contratos de operación petrolera que se han otorgado desde 1977. La pregunta relevante es si la participación de Enap ha inhibido o sustituido la participación de inversionistas privados en el mercado de exploración.

Existen distintas explicaciones alternativas para el hecho de que Enap esté involucrada en todos los contratos de operación existentes. Una primera alternativa, es que éste sea el resultado del poder monopólico de Enap en este mercado en Chile y de que su propiedad sea $100 \%$ estatal. El Estado es dueño de los yacimientos y de Enap, por lo que puede potencialmente abusar de su posición monopólica en la propiedad de los yacimientos y exigir a un inversionista privado la participación de Enap en el contrato de operación petrolera a cambio de otorgárselo.

Una segunda alternativa, es que Enap tenga mejor información respecto a la potencial ubicación y características geológicas de yacimientos de petróleo en Chile, en cuyo caso son los inversionistas privados los que están interesados en asociarse con Enap. Adicional- 
mente, Enap tiene la ventaja de que puede obtener servidumbres de paso más fácilmente, ya que no requiere obtener los permisos que necesita un privado ${ }^{10}$.

Es imposible poder determinar, a partir de la información disponible, cuál de las dos alternativas anteriores es la que explica la presencia de Enap en todos los Ceop a partir de 1977. Sin embargo, hay dos argumentos por los cuales consideramos que la segunda alternativa es más probable y que las barreras a la entrada efectivas en el mercado de exploración y explotación de petróleo no han sido tan altas en Chile.

Los dos argumentos se basan en la existencia de Sipetrol y sus resultados. El primero es el hecho de que Enap, a través de Sipetrol, ha logrado asociarse con otras empresas para participar en mercados de exploración y explotación fuera de Chile. Lo anterior muestra que Enap tiene un grado de conocimiento y pericia en este mercado que es valorado por otras empresas, las cuales optan por asociarse con Enap en mercados geográficos donde el Estado de Chile no tiene facultades legales para impedir la entrada de esas empresas.

El segundo argumento se basa en el hecho de que Enap, a través de Sipetrol, ha concentrado sus esfuerzos de exploración y explotación en el extranjero y no en Chile, donde podría tener un monopolio si el Estado usara sus facultades para bloquear el acceso a nuevas empresas. Lo anterior constituye, en parte, evidencia de que el mercado de exploración y explotación de petróleo no es atractivo en Chile probablemente por condiciones geológicas.

Una característica importante entonces en el upstream es el potencial libre acceso del sector privado a la explotación y exploración. En la práctica, probablemente producto del monopolio que históricamente tuvo y del bajo potencial de recursos petroleros en el país, Enap es la única empresa que produce petróleo crudo en Chile. Es importante recordar que aun cuando Enap es el único productor de crudo en el país, la importancia del petróleo doméstico en el mercado es menor, ya que la gran mayoría del consumo interno se satisface con importaciones. En el año 2007 la oferta de petróleo crudo doméstico en Chile representó apenas el 1,2\% de la oferta total.

Si bien el mercado de exploración y explotación de petróleo en Chile es pequeño y tiene muy poco potencial de crecimiento, sería

${ }^{10}$ Es importante señalar que en el caso particular de los Ceop, éstos incluyen servidumbres de paso. 
importante que se avanzara en eliminar las potenciales barreras a la entrada en el mercado. No hay evidencia de que el Estado haya usado sus facultades para impedir o limitar el acceso a este mercado, pero potencialmente podría hacerlo en cualquier momento, en particular si Enap fuese una empresa privada.

En este sentido, es necesario avanzar en dos aspectos. El primero es implementar un sistema de concesiones similares a las concesiones mineras en Chile, donde los inversionistas privados pueden asumir completamente el riesgo en la etapa de prospección y exploración con la certeza de que tendrán la propiedad sobre los retornos de esa inversión, si es que los hay ${ }^{11}$. El segundo aspecto, si bien de segundo orden, es igualar las condiciones para solicitar derechos de paso para todas las empresas en el mercado.

\subsection{Mercados downstream: Refinación}

La producción interna de derivados del petróleo es realizada exclusivamente por Enap. Adicionalmente, Enap es la única empresa importadora de petróleo crudo. Nuevamente, la pregunta relevante es si hay en este mercado barreras a la entrada que le otorguen algún poder de mercado a Enap. Si un distribuidor mayorista no quisiera comprarle productos refinados a Enap tiene tres alternativas potenciales: i) importar crudo y comprarle los servicios de refinería a Enap; ii) importar crudo y construir una refinería; y iii) importar productos refinados.

La primera alternativa no está disponible en el mercado porque Enap no ofrece servicios de refinación y su política comercial es no hacerlo aunque sus refinerías tengan capacidad ociosa. De hecho, en los 80 y 90 las refinerías de Enap funcionaron, en promedio, a un 50\%

${ }^{11}$ En Chile, toda persona natural o jurídica puede hacer manifestaciones o pedimentos y adquirir concesiones mineras en trámite o constituidas, o cuotas en ellas. Las concesiones mineras son derechos reales e inmuebles, distintos e independientes del dominio del predio superficial, son transferibles y transmisibles, susceptibles de hipoteca y otros derechos reales y, en general, de todo acto o contrato, y se rigen por las mismas leyes civiles que los demás inmuebles. Las concesiones mineras se constituyen por resolución judicial dictada en un procedimiento no contencioso, sin intervención decisoria alguna de otra autoridad o persona. La concesión minera debe ser amparada mediante el pago de una patente anual y son de dos tipos: concesión de exploración y concesión de explotación. El trámite de constitución de concesión se lleva a cabo ante los tribunales civiles del lugar en donde se tenga intenciones de explorar o explotar minerales, según sea el caso. 
y un $70 \%$ de capacidad respectivamente y la alternativa de importar crudo y refinarlo en Enap no estaba disponible.

La segunda opción, de acuerdo a conversaciones con las principales empresas de la industria, requiere de un monto de inversión del orden de los US $\$ 1.000$ millones si se quiere construir una refinería a partir de cero. El problema principal, sin embargo, es que el tamaño del mercado chileno no permite la existencia de una nueva refinería, ya que una refinería construida con el tamaño mínimo de escala eficiente tendría capacidad ociosa por un largo período de tiempo.

La tercera opción es posible desde 1978, año en que se permitió la libre importación de petróleo crudo y productos refinados. De hecho, como se mencionó en la sección 2.3, un tercio de las importaciones de productos refinados en Chile fueron realizadas por las distribuidoras mayoristas en el año 2006.

La pregunta relevante entonces pasa a ser si la libertad de importación de productos derivados es suficiente como para limitar significativamente el potencial poder de mercado que tiene Enap en refinación. La política actual de precios de Enap consiste en cobrar un precio por cada producto refinado que es apenas un poco más bajo que el costo de importación para un comprador en Chile. Para estos efectos Enap utiliza como precio de paridad de importación el precio de los productos refinados en el Golfo de México puestos en Concón. Enap utiliza entonces una política de precio límite que si bien refleja que su poder monopólico se ve limitado por la potencial importación directa de petróleo por parte de sus clientes en Chile, igualmente le permite a Enap tener utilidades económicas superiores a cero (que son las que obtendría si el mercado chileno de refinación fuera perfectamente competitivo).

Adicionalmente, es necesario considerar si Enap puede potencialmente aumentar el precio límite que cobra a los distribuidores mayoristas de combustibles en forma sostenida sin reducir su participación de mercado en productos refinados. Hay tres tipos de estrategia o restricciones potenciales que Enap podría usar para limitar la competencia de petróleo importado. La primera, consiste en colocar restricciones en los contratos con sus clientes, los cuales pueden tener cláusulas de cantidad o plazos que dejen cautivos a los compradores e impidan en la práctica la importación de productos refinados por parte de ellos. No es posible saber si este es el caso o no, porque no hay acceso a los contratos, pero al menos en conversaciones con distribui- 
dores mayoristas este no parece ser un tema relevante. Además, no ha habido presentaciones contra Enap en los tribunales de libre competencia por este tema.

Una segunda alternativa que podría utilizar Enap consiste en aprovechar las economías de ámbito y de escala que provee su logística para la importación de productos refinados. Si esto fuera posible, Enap podría importar una cantidad suficiente de productos refinados que impidan que los distribuidores mayoristas alcancen, por el tamaño del mercado en Chile, las economías de escala necesarias (tamaño de barcos y capacidad de almacenamiento) como para competir con los precios que cobra Enap. Si bien es imposible que Enap pueda bloquear (foreclosure) el mercado de importación de productos derivados, ya que las empresas distribuidoras mayoristas poseen terminales marítimos y almacenamiento propios, sí podría potencialmente cobrar un precio límite superior al de paridad de importación. Lamentablemente, no hay acceso público a datos que permitan, en primer lugar, cuantificar la magnitud potencial de este efecto, y en segundo lugar, contrastar empíricamente esta hipótesis.

Finalmente, una tercera posibilidad es utilizar precios predatorios cada vez que un distribuidor mayorista importa un determinado volumen de productos refinados. En general, una política de precios predatorios podría no ser creíble para los entrantes en el mercado ya que no es una política sostenible en el largo plazo. Sin embargo, el hecho de que Enap sea una empresa estatal, potencialmente con acceso ilimitado a fondos, hace que ésta pueda ser una política creíble y Enap pueda construir una reputación que limite la entrada de importaciones de productos refinados ${ }^{12}$.

Durante la década de los 80, la participación de Enap en las importaciones totales de productos refinados fue siempre superior al 83\% y llegó a ser de 98\% a principios de los 90, lo cual pudo haber sido consistente con una política agresiva de precios que inhibía las importaciones. Sin embargo, observar una fracción baja de importaciones por parte de los distribuidores mayoristas también es consistente con un tamaño de mercado doméstico que puede ser abastecido completamente con la capacidad de refinación de Enap y donde las refinerías son eficientes en su producción.

12 Véanse Kreps y Wilson (1982), Milgrom y Roberts (1982) y Selten (1978). 
Si bien no hay datos disponibles que permitan determinar si Enap usó en algún momento una política de precios predatorios (especialmente en los 80 y a principios de los 90) da la impresión, a partir de los precios observados de los combustibles y los márgenes de las empresas distribuidoras, que esta no es una política que haya usado en los últimos años ${ }^{13}$.

Un cambio importante ocurrido en enero de 2004 en el mercado de las gasolinas y el diésel en la Región Metropolitana, lo constituye el Decreto Supremo 58 sobre el plan actualizado de prevención y descontaminación atmosférica de la Región Metropolitana, el cual reduce los límites máximos para la cantidad de benceno y azufre en las gasolinas ${ }^{14}$ y la de azufre en el diésel ${ }^{15}$. Si bien Enap no tiene injerencia en la normativa ambiental que establece la Conama, este cambio en las normas ambientales de la gasolina y el diésel afectan el grado de competencia potencial que representan las importaciones de productos derivados para Enap y le permiten potencialmente usar un precio límite mayor al que podría usar en las condiciones previas. La razón para esto último es que varias fuentes potenciales de importación de gasolinas y diésel no cumplen con la normativa para la Región Metropolitana que es el mercado más grande del país.

Finalmente, es necesario estudiar en el futuro el impacto que ha tenido la fusión de las dos refinerías en los precios que cobra Enap. Es posible que la fusión permita aprovechar algunas economías de escala y facilite la coordinación logística, lo cual permitiría a Enap bajar sus costos de refinación y ser más eficiente. No hay razones para pensar que la fusión permita aumentar el poder monopólico de las refinerías, ya que esta es una integración horizontal de dos filiales del mismo dueño. Sin embargo, si se detectara un abuso de poder monopólico por parte de Enap y no hubiera economías de escala importantes en la producción de productos refinados usando dos refinerías, una solución potencial para generar más competencia sería que el tribunal de defensa de la libre competencia obligara a Enap a vender una de las refinerías, medida que producto de la fusión se ha hecho claradamente más difícil.

${ }^{13}$ En conversaciones con algunas empresas mayoristas, algunas de estas empresas señalaron que durante los 80 cada vez que un distribuidor mayorista importaba combustibles directamente, Enap bajaba los precios.

${ }^{14}$ Se permite un máximo de $1 \%$ de benceno y 30 ppm de azufre.

${ }^{15}$ Se reduce el máximo permitido de 3.000 ppm a 50 ppm. 


\subsection{Mercados downstream: Almacenamiento y transporte}

Las relaciones patrimoniales descritas previamente muestran que en Chile existe un grado importante de integración vertical de las empresas que operan en los distintos mercados hacia la logística. Enap es la única empresa en el mercado de refinación y está integrada hacia el almacenamiento a través de su ex filial Emalco, hacia el transporte marítimo a través de Sonamar y hacia el transporte por oleoductos a través de Sonacol. Igual situación ocurre con las tres principales empresas distribuidoras mayoristas (Copec, Esso y Shell).

La integración vertical en estos casos puede generar economías de alcance que aumenten la eficiencia en la asignación de recursos, pero también pueden facilitar la exclusión de mercado y otras prácticas que reducen la competencia y distorsionan la asignación de recursos. En efecto, por un lado la integración vertical es productivamente más eficiente porque internaliza las externalidades producidas por la decisión de marginar la demanda que hacen las empresas relacionadas; por el otro lado, la separación vertical es asignativamente eficiente al reducir las ventajas estratégicas que sigue un conglomerado en la industria frente a terceros, es decir, genera mercados más competitivos ${ }^{16}$.

En el mercado de almacenamiento de combustibles líquidos, si bien las principales distribuidoras mayoristas invirtieron fuertemente durante los 90 y cuentan con almacenamiento propio, Enap, vía la ex Emalco, sigue siendo un actor importante con una capacidad total de almacenamiento en el país que supera el 70\%. Geográficamente, esta empresa estatal dispone de plantas de almacenamiento en el centro y sur del país, de la V a la VIII Región, además de la XII. En cada una de estas regiones es líder en capacidad, siendo en la Región Metropolitana su menor participación de almacenamiento con cerca de dos tercios de la capacidad global.

En el análisis de este mercado, desde el punto de vista de la organización industrial, la pregunta relevante es si existe la posibilidad de aumentar las barreras a la entrada o incluso excluir del mercado a nuevos competidores. Enap no sólo almacena su propio combustible

\footnotetext{
${ }^{16}$ Más detalles junto a los argumentos teóricos respecto a las ventajas y desventajas de la integración vertical se encuentran en Aghion y Bolton (1987), Galetovic (2003), Grossman y Hart (1986), Joskow (1985), Spengler (1950), Vickers (1995) y Williamson (1985).
} 
sino que además presta servicios de almacenamiento a terceros. Esta política de acceso abierto ha permitido que algunas empresas puedan entrar al mercado de distribución de combustibles sin tener que invertir en almacenamiento. Ese fue el caso de Apex, Enex, Gazpesa y Texaco en los 80 y el de YPF en los 90. Sin embargo, las cláusulas de los contratos y las tarifas de Enap (Emalco) tienen algunos elementos que pueden dificultar la entrada de nuevas empresas en el mercado de distribución. En particular, se establecen requisitos mínimos de capacidad para el arriendo de almacenaje y se exige adicionalmente arrendar capacidad para al menos dos combustibles distintos. Estas cláusulas favorecen a los distribuidores mayoristas que ya están en el mercado frente a un potencial entrante $y$, adicionalmente, dificultan la importación de productos derivados, con lo cual Enap puede reducir la competencia que enfrenta de las importaciones en el mercado de refinación.

En el caso de las tarifas, se cobra una tarifa de almacenaje que es no discriminatoria y una tarifa de entrega que es mayor para el caso de entrega de combustible en isla de carguío que para la entrega en oleoducto. Si bien el costo de entregar en isla de carguío es más alto que el de entregar en oleoducto, lo cual justifica la diferencia de tarifa, esta diferencia de precios puede constituir una barrera a la entrada si sólo pueden acceder a ellos los distribuidores mayoristas que comparten la propiedad de los oleoductos a través de Sonacol.

Finalmente, es importante señalar que si bien Enap sigue actualmente una política de acceso abierto a sus instalaciones de almacenamiento, en la práctica la capacidad de almacenaje que otras empresas arriendan es sólo para productos comprados a Enap. No hay información disponible que indique cuáles serían las cláusulas y las tarifas para una empresa que decida importar productos derivados, no comprar nunca a Enap y arrendarle almacenamiento.

En los mercados de transporte de combustibles, los productos refinados son transportados a los distribuidores mayoristas a través de oleoductos, barcos o camiones. En la práctica, al año 2007 más 7,5 $\mathrm{Mm}^{3}$ de productos refinados destinados al mercado nacional se transportaron a través de la red de oleoductos en el país, de los cuales gran parte son propiedad de Sonacol. Como se señaló previamente, la estructura de propiedad de Sonacol está compuesta por las principales compañías distribuidoras de combustibles líquidos junto a Enap. Adi- 
cionalmente, existe una red de oleoductos que conectan la refinería Enap Bío Bío con la planta de almacenamiento en San Fernando y otra red de oleoductos en Magallanes, ambas redes de propiedad de Enap Refinerías S.A.

Una de las características relevantes en este mercado es que en el caso de los oleoductos las inversiones son irreversibles, lo cual abre la posibilidad de ejercer algún tipo de poder monopólico, porque el transporte de crudo y sus derivados por oleoducto es más rápido y confiable que por camión o por vía marítima.

Sin duda que la alternativa al uso de oleoductos para el transporte de derivados del petróleo son los camiones. Sin embargo, este tipo de transporte no es un sustituto tan cercano debido, principalmente, a la dificultad de transportar grandes volúmenes de productos. Por ello, si bien existe la posibilidad de ejercer algún tipo de poder monopólico por parte de Sonacol, dicho poder estaría limitado por la posibilidad de transportar productos a través de camiones. La sustitución imperfecta entre ambos servicios de transporte genera de igual forma un espacio para usar la estrategia de precio límite y cobrar por el uso de oleoductos un precio un poco menor que el costo de transportar combustibles usando camiones, lo cual le permite a Sonacol capturar una renta que no tendría si este mercado fuera más competitivo.

Más aún, si bien Sonacol posee una política de acceso abierto con tarifas no discriminatorias, es importante notar que producto de la estructura de propiedad de la empresa, los incentivos que tiene Sonacol son para cobrar tarifas a costo marginal a sus socios (Enap, Copec, Shell y Esso) y tarifas de precio límite al resto de las empresas en el mercado de distribución. Es posible que la amenaza creíble de una acusación ante el Tribunal de Defensa de la Libre Competencia por parte de una empresa discriminada inhiba en algún grado una política de precios de ese tipo. Sin embargo, una política de acceso abierto con tarifas no discriminatorias no garantiza la existencia de precios competitivos en el uso de los oleoductos.

De hecho, si no existiera la alternativa de transporte por camión, por ejemplo, Sonacol podría cobrar una tarifa monopólica no discriminatoria. En la práctica, dicha tarifa sólo afectaría a las empresas que no tienen propiedad en Sonacol, ya que los socios recuperarían la diferencia de precios pagada entre el precio monopólico y el precio competiti- 
vo a través de los dividendos que repartiría Sonacol a sus socios ${ }^{17}$. Este ejemplo, sirve para mostrar la importancia de estudiar empíricamente el grado de sustitución real que existe entre el transporte por oleoductos y el transporte por camiones, junto con cuantificar la diferencia entre el precio límite que cobra Sonacol y un precio competitivo. La escasa evidencia disponible, si bien con datos para 1992, es consistente con la existencia de rentas monopólicas en el transporte por oleoductos (Fuentes, Paredes y Vatter, 1994).

Adicionalmente, es importante señalar que la existencia de una empresa como Sonacol en un mercado con algunas características de monopolio natural producto de la irreversibilidad de las inversiones en oleoductos, y cuya propiedad es compartida por las tres principales distribuidoras mayoristas de combustibles del mercado, constituye un mecanismo que puede facilitar la colusión de dichas empresas ${ }^{18}$.

No hay ningún tipo de información ni evidencia de que efectivamente exista colusión por parte de las empresas distribuidoras que comparten propiedad en Sonacol, pero el compartir la propiedad de los oleoductos no sólo facilita la potencial coordinación entre las empresas sino que también permite observar el comportamiento de cada una de ellas y detectar y castigar violaciones a un acuerdo. Por ejemplo, si las empresas quisieran ponerse de acuerdo para mantener sus participaciones de mercado constantes podrían repartir la capacidad de uso de los oleoductos que le corresponde a cada una en base a su participación de mercado. Si alguna empresa no respeta el acuerdo y comienza a vender una mayor cantidad de combustible que la que le correspondía, las otras empresas pueden no sólo detectar un mayor uso del oleoducto por parte de la empresa que violó el acuerdo, sino que además pueden castigarla y disminuirle el acceso al transporte por oleoductos.

Mantener un acuerdo colusivo es obviamente mucho más complejo y difícil que como se ha planteado en el ejemplo anterior, pero el objetivo es simplemente ilustrar algunos mecanismos que facilitan la colusión entre empresas y que no podrían implementarse si dichas

${ }^{17}$ Los estatutos de Sonacol restringen la tarifa cobrada a un máximo de 15\% de la rentabilidad operacional antes de impuestos (Roai), lo cual no sólo muestra que un caso como el del ejemplo es posible sino que también refleja la capacidad de utilizar a Sonacol para llegar a acuerdos en torno a variables estratégicas de competencia entre un grupo de competidores en la industria.

${ }^{18}$ Véase por ejemplo Abreu, Milgrom y Pearce (1991) y Kühn (2001). 
empresas no compartieran la propiedad de una facilidad con algunas características monopólicas.

A partir del trabajo de Green y Porter (1984) es conocido que la observabilidad imperfecta de las acciones de las empresas rivales hace más difícil la colusión. Por ello, mecanismos de intercambio de información, en particular sobre precios y cantidades individualizadas en el pasado y sobre precios y producción futura, facilitan la colusión entre las empresas que participan de ese intercambio privado de información. Sin duda que hay intercambios de información que generan ganancias de eficiencia, pero en general esos intercambios se refieren a información agregada del mercado y a información pública sobre aumentos de capacidad. Es altamente improbable que información individualizada de precios, cantidades y/o producción generen ganancias de eficiencia.

En ese sentido, Sonacol facilita, por su estructura de propiedad, que los principales actores del mercado intercambien información. Es relevante considerar entonces no sólo si dicha información genera ganancias de eficiencia, sino que fundamentalmente si no es posible obtener esas ganancias de eficiencia a través de otro mecanismo que no facilite la colusión.

Tal como se mencionó en la segunda sección de este artículo, Enap junto a Copec y a las principales empresas navieras chilenas formaron Sonamar a partir de la antigua División Marítima de Sonacol. Esta empresa ofrece servicios de transporte por mar hacia y desde los puntos más alejados de Chile y es propietaria de la flota de transporte petrolero más importante del país. Si bien el transporte marítimo puede ser un sustituto del transporte por oleoductos, en el caso de Chile, por razones geográficas, es más bien un complemento. Por esta razón es improbable que la presencia de Enap y Copec en ambas empresas que ofrecen sus servicios de transporte en estos mercados (Sonacol y Sonamar) reduzca por sí misma, en forma importante, el grado de competencia en el transporte de combustibles líquidos.

Lo que parece cuestionable es que siendo empresas potencialmente competitivas de la ex División Marítima de Sonacol, empresas navieras del país sean partícipes de la nueva empresa Sonamar, creada en el año 2005. Sería ciertamente interesante poder realizar un estudio que evalúe empíricamente las variaciones de los costos del transporte 
de combustibles líquidos derivados del petróleo antes y después de la integración entre empresas (potencialmente) rivales en un mercado de por sí concentrado.

\subsection{Mercados downstream: Distribución mayorista y minorista de combustibles líquidos}

Como se señaló previamente en la descripción de estos mercados, la liberalización de la distribución mayorista en 1978 junto con la libertad de precios de los derivados del petróleo en $1982^{19}$, permitieron la entrada de nuevas empresas a la industria y una mayor competencia.

En 1981 entró Comar al mercado, en 1984 lo hicieron Abastible, Apex y Enex y en 1985 Gazpesa, lo cual disminuyó el grado de concentración en este mercado en forma importante en un período de tiempo no muy largo. Sin embargo, en 1987 Apex fue comprada por Copec y Enex por Shell. Posteriormente, en 1995 entró al mercado YPF (luego Repsol-YPF y actualmente Terpel) adquiriendo primero los 60 locales de Gazpesa y posteriormente en 2001 los de Texaco. Finalmente, en 2007 Terpel compró Repsol-YPF, adquiriendo de esta forma doscientos locales en Chile. Actualmente, el mercado de distribución se encuentra de nuevo concentrado en pocas empresas, donde las empresas ya establecidas (incumbents) siguen teniendo una participación superior al $90 \%$ y además están verticalmente integradas hacia los mercados de almacenaje y transporte.

Es importante separar en el análisis la integración vertical entre distribución mayorista y minorista de la integración vertical entre empresas mayoristas y logística (almacenamiento y transporte por oleoductos).

La integración vertical entre empresas mayoristas y minoristas puede analizarse con un simple modelo de agente y principal, donde el mayorista es el principal que necesita del minorista, un agente, para poder vender productos refinados a consumidores finales. La inversión en los activos necesarios para vender gasolina a consumidores finales es compartida, generalmente, entre el principal y el agente (terreno, estanques y surtidores). Sin embargo, el esfuerzo en las ventas y en la calidad del servicio es responsabilidad del agente y no constituye una

${ }^{19}$ Con excepción del precio del GLP de la XI y XII Región, que se liberó posteriormente. 
variable $100 \%$ observable por el principal. Como los incentivos del agente y del principal no están completamente alineados y hay algunas variables no observables o difíciles de monitorear, hay incentivos para incorporar algunas cláusulas de restricción vertical en los contratos que minimicen el problema de agencia ${ }^{20}$. Adicionalmente, si hay inversiones irreversibles involucradas en la relación entre dos empresas, la integración vertical impide el comportamiento oportunista que surge a raíz de la imposibilidad práctica de escribir contratos completos que gobiernen las relaciones contractuales entre las dos partes.

Dado el carácter específico de algunas inversiones, las partes involucradas están en presencia de una "quasi-renta” generada a partir de la situación de lock-in en que se encuentran. Esto genera, ex post, incentivos a comportamientos oportunistas que permiten extraer un mayor porcentaje de las "quasi-rentas" generadas. El resultado de este comportamiento oportunista ex post es la subinversión o hold-up. Una forma de minimizar este problema es entablar alianzas de largo plazo o aun fusiones que garanticen a las partes que no habrá comportamiento oportunista ex post.

La evidencia empírica al respecto muestra que en algunas industrias las ganancias de la integración superan sus eventuales costos y así las empresas terminan integrándose, estableciendo alianzas estratégicas de largo plazo (Joskow, 1985) o creando relaciones de negocios duraderas con muy pocas empresas con el objeto de generar reputación de seriedad en la industria (Hölmstrom y Roberts, 1998).

La integración vertical de empresas de distribución mayorista con empresas de distribución minorista puede entonces generar algunas economías de ámbito, alinear incentivos entre el agente y el principal y permitir niveles de inversión óptima. No hay razones que permitan pensar que haya efectos negativos en el grado de competencia del mercado, por lo que desde el punto de vista de la asignación de recursos la integración vertical en distribución tiene potenciales beneficios y muy pocos costos.

En el caso de la integración vertical donde empresas competidoras en distribución comparten propiedad de las empresas en transporte y almacenaje, tal como se señaló previamente, se facilita la colusión en el mercado de distribución y es posible aumentar las barreras a la entrada en el mismo mercado.

${ }^{20}$ Véase por ejemplo Shepard (1993). 
Si bien la estructura de propiedad y el grado de integración vertical de esta industria indican que sería posible tener un grado de competencia no muy alto en el mercado de distribución minorista, la escasa evidencia empírica muestra que éste es un mercado relativamente competitivo. Para sostener esta conclusión en forma más robusta sería necesario hacer un estudio empírico del mercado usando técnicas de la nueva organización industrial empírica, lo cual requiere acceso a datos más desagregados que no están disponibles ${ }^{21}$.

Sin embargo, la teoría económica predice que en el largo plazo en un mercado perfectamente competitivo los aumentos en los costos de producción se traspasan uno a uno a los consumidores, es decir, la tasa de pass-through es uno. Esto permite hace un test indirecto pero simple del grado de competencia en un mercado. Borenstein y Shepard (2002), por ejemplo, estudian el impacto de los shocks de precios del petróleo en los precios de mayoristas en 188 mercados de gasolinas. Una de las conclusiones del estudio es que, efectivamente, en los mercados en que hay empresas con algún grado de poder de mercado el ajuste de los precios es más lento (pass-through menor que uno) que en los mercados más competitivos.

Balmaceda y Soruco (2008) estiman la tasa de pass-through para el mercado de distribución de gasolinas en Chile y obtiene tasas estimadas de pass-through que van desde 0,839 para gasolinas de 97 octanos a 0,911 para gasolinas de 93 octanos, lo cual provee evidencia de que el mercado de distribución es bastante competitivo en el largo plazo. Sin embargo, los resultados muestran que el precio a consumidores finales aumenta un $6,2 \%$ más que el aumento efectivo en el precio de refinería y cae en un 10,5\% menos que lo que cae el precio de refinería. La evidencia de asimetría en las respuestas de precios ante cambios en los precios de refinería es consistente con la existencia de poder de mercado en el corto plazo y, en particular, con la posibilidad de que el anuncio semanal de precios que realiza Enap funcione como un punto focal que facilita la colusión ${ }^{22}$. Lamentablemente, este estudio no inclu-

${ }^{21}$ Véase Bresnahan (1989), Panzar y Rosse (1987), Berry, Levinsohn y Pakes (1995), Nevo (2001).

${ }^{22}$ La explicación alternativa, basada en costos de búsqueda, requiere la existencia de consumidores desinformados respecto a shocks de costos o empresas desinformadas respecto a los shocks de costos de las otras empresas. Ambos grados de desinformación son improbables porque Enap anuncia públicamente sus precios y el precio esperado de las gasolinas cada semana, lo cual es informado ampliamente por la prensa. 
ye los precios del kerosene en el análisis, que es el combustible líquido en el que se observan márgenes sistemáticamente más altos que en el resto de los combustibles. Por esta razón, puede ser importante replicar el trabajo de Balmaceda y Soruco (2008) para el mercado del kerosene, pero no hay datos públicos que lo permitan.

\subsection{Conclusiones del análisis y una agenda de trabajo hacia el futuro}

De la caracterización de los aspectos de organización industrial y la información disponible, es posible concluir que si bien no hay evidencia del ejercicio de poder de mercado o de conductas que atenten contra la libre competencia, sí existen potenciales barreras a la entrada en algunos mercados que hacen posible que algunos actores usen su posición dominante para extraer rentas monopólicas en algún grado. En algunos casos, estas potenciales prácticas se facilitan aún más por las relaciones de propiedad verticales que coexisten en la industria.

En el mercado de exploración y explotación de petróleo, no hay total transparencia e información respecto a cómo el Estado decide la participación de inversionistas privados en los Ceop, lo que permite un grado de discreción que puede limitar la entrada. Adicionalmente, Enap tiene ventajas legales frente a un inversionista privado respecto a las servidumbres de paso necesarias para desarrollar estas actividades.

En el mercado de la refinación, Enap podría potencialmente extraer en forma parcial una renta monopólica usando la estrategia de precio límite. La magnitud de dicha renta está limitada por las importaciones de combustibles que puedan realizar las compañías distribuidoras mayoristas directamente, razón por la cual esa renta podría incrementarse si hay algún tipo de comportamiento estratégico que dificulte la importación de productos derivados por parte de distribuidores de combustible.

En el almacenaje de combustibles, Enap tiene una posición dominante y el tipo de cláusulas que usa en los contratos puede dificultar la importación de combustibles por parte de potenciales competidores. Adicionalmente, algunas cláusulas de los contratos favorecen a los mayoristas ya establecidos en el mercado de distribución, lo cual puede dificultar la entrada de nuevos competidores en el mercado de gasolinas. 
En el transporte de combustibles líquidos, la estructura de propiedad de Sonacol facilita la colusión y la inversión irreversible que constituyen los oleoductos le entrega un cierto grado de poder monopólico. La posibilidad de ejercer ese poder monopólico está limitada por la alternativa del transporte por camiones, pero la creación de Sonamar no es precisamente un evento procompetitivo ya que incluyó en el negocio a dos de los principales rivales potenciales de la empresa que realizaba el servicio de transporte marítimo de combustible en el país.

Una de las características de esta industria es la falta de información, la desactualización de la información que hay y la dificultad para acceder a datos básicos que permitan generar evidencia empírica respecto al funcionamiento de cada mercado ${ }^{23}$. Por ello, los potenciales problemas de política de competencia encontrados a partir del análisis de organización industrial constituyen indicios que deberían orientar futuras investigaciones empíricas para sustentar decisiones de política económica que garanticen el funcionamiento competitivo de la industria del petróleo y sus derivados líquidos en Chile.

En resumen, del análisis de organización industrial del sector de combustibles líquidos se puede concluir que existen algunos parámetros críticos que deben ser cuantificados para obtener conclusiones más precisas respecto al grado de competencia en cada mercado. En particular, consideramos importante cuantificar el grado de sustitución y diferencias de costo entre transporte de combustible por camión y oleoductos, la magnitud de las economías de ámbito que se generan con la integración vertical de la refinación con el almacenamiento, el transporte por oleoductos y los terminales marítimos; la política de precios seguida en el transporte marítimo de los derivados del petróleo; la magnitud de las economías de ámbito que se generan con la integración vertical de la distribución mayorista con el almacenamiento, el transporte por oleoductos y los terminales marítimos; la diferencia de costos y tarifas para el almacenamiento con entregas en islas de carguío y oleoductos; y, el diferencial de precios entre el precio de paridad cobrado por Enap y el precio de importación para un potencial entrante al mercado de distribución.

${ }^{23}$ Otros investigadores se han enfrentado a la misma dificultad. Ferrer (2006), por ejemplo, menciona que "existe una profunda falta de información cuantitativa y una baja disposición de parte de algunas distribuidoras a entregar información”. De igual forma, Gómez-Lobo y Córdova (2006) señalan que "la calidad de la información disponible para este estudio no fue la óptima”. 


\section{RECOMENDACIONES DE POLÍTICA}

Más allá de los estudios empíricos que se puedan realizar para cuantificar algunos riesgos competitivos o la existencia de poder de mercado, hay algunas reformas en la estructura de funcionamiento de algunos de los mercados en la industria del petróleo que sin duda serían procompetitivas y que debieran realizarse.

Es bastante claro que el excesivo poder de Enap en el mercado upstream les otorga muy poca flexibilidad a potenciales inversionistas privados. La empresa estatal cuenta con ventajas no justificadas económicamente que generan incentivos insuficientes para que un inversionista privado invierta en prospección y exploración. Consideramos más razonable establecer un sistema de concesiones de prospección, exploración y explotación similar al que existe en el sector de la minería, donde el proceso es no contencioso y no hay espacio para la discrecionalidad de la autoridad. Un criterio como éste no sólo entrega certeza jurídica sino que garantiza además que los potenciales retornos de la inversión sean capturados por el inversionista.

En el mercado downstream, hay riesgos serios para la libre competencia producto de la integración vertical que cruza estos mercados. Una medida procompetitiva consiste en exigir la constitución de empresas funcionalmente separadas de sus matrices en refinación, transporte y almacenamiento, tanto para Enap como para las distribuidoras mayoristas (y, especialmente para Copec). La separación funcional de las empresas genera transparencia en los mercados y permite reducir las posibles prácticas discriminatorias o el extender el potencial ejercicio de poder monopólico de un mercado hacia otro. Sólo hay que cuidar, en la forma de implementarla, que esta medida no inhiba artificialmente la integración vertical en mercados donde la concentración puede tener efectos de eficiencia productiva importantes. Como segunda medida, complementaria a la primera, se debe exigir que todas las empresas que operan mercados altamente concentrados se sometan voluntariamente a la fiscalización de la Superintendencia de Valores y Seguros y entreguen información pública equivalente a la que entregan las sociedades anónimas abiertas.

De igual forma, es posible avanzar en otros aspectos que tienen el potencial de incentivar la competencia en los mercados relevantes y no tienen el riesgo de generar mayores costos para el desarrollo de la 
industria. En primer lugar, se requiere generar mayor información y hacer más transparente el funcionamiento de los mercados y los principales actores involucrados, especialmente los que tienen una posición claramente dominante en su mercado. En particular, se requiere mejorar la transparencia y actualización de los datos que generan los organismos públicos relacionados con la industria. En segundo lugar, se requiere reducir el número de organismos estatales involucrados, delimitando claramente las funciones y responsabilidades de cada uno y estableciendo reglas claras respecto a su comportamiento, evaluación y transparencia (contabilidad y transparencia regulatoria).

En conclusión, ni para la estructura ni el funcionamiento de la industria petrolera en Chile parece aconsejable por ahora establecer regulaciones muy complejas. Más bien se requiere la aprobación de un simple marco regulatorio, que ordene toda la normativa que afecta al sector y que establezca y determine principios económicos básicos que fomenten la competencia, la transparencia y la inversión en los distintos mercados de la industria. Para ello es necesario establecer libertad de precios, de importación, políticas de acceso abierto y no discriminatorio en facilidades esenciales, tarifas públicas en la logística, y entrega de información que permita a todos los actores del mercado, a la Fiscalía Nacional Económica y al Tribunal de Defensa de la Libre Competencia denunciar y sancionar cualquier práctica anticompetitiva en algunos de los mercados de la industria de petrolera en Chile.

\section{REFERENCIAS}

Abreu, D., P. Milgrom y D. Pearce (1991): "Information and Timing in Repeated Partnerships”. En Econometrica 59, 1713-1733.

Aghion, P. y P. Bolton (1987): “Contracts as a Barrier to Entry”. En American Economic Review 77 (3).

Alm, J., E. Sennoga y M. Skidmore (2008): "Perfect Competition, Urbanization, and Tax Incidence in the Retail Gasoline Market”. En Economic Inquiry (por aparecer).

Arellano, S. y S. Valdés, editores (2006): Los Mercados de Combustibles Líquidos en Chile, Ediciones P. Universidad Católica de Chile.

Balmaceda, F. y P. Soruco (2008): “Asymmetric Dynamic Pricing in a Local Gasoline Retail Market”. En Journal of Industrial Economics 56 (3), 629-653.

Berry, S., J. Levinsohn y A. Pakes (1995): “Automobile Prices in Market Equilibrium”. En Econometrica 63, 841-890. 
Borenstein, S. y A. Shepard (2002): "Sticky Prices, Inventories, and Market Power in Wholesale Gasoline Markets”, RAND Journal of Economics 33 (1), 116-139.

Bresnahan, T. (1989): "Empirical Studies of Industries with Market Power”. En R. Schmalensee y R. D. Willig, Handbook of Industrial Economics, Volumen II. Elsevier Science Publishers.

Chouinard, H. y J. Perloff (2004): “Incidence of Federal and State Gasoline Taxes”. En Economics Letters 83 (1), 55-60.

Delipalla, S. y O. O’Donell (2001): “Estimating Tax Incidence, Market Power and Market Conduct: The European Cigarette Industry”. En International Journal of Industrial Organization 19, 885-908.

Doyle, J. y K. Samphantharak (2008): “\$2.00 Gas! Studying the Effects of Gas Tax Moratorium”. En Journal of Public Economics 92 (3-4), 869-884.

Ferrer, J. C. (2006): "Bundling en Promociones para la Distribución de Combustibles”. En S. Arellano y S. Valdés (eds.), Los Mercados de Combustibles Líquidos en Chile. Ediciones P. Universidad Católica de Chile.

Fosco, C. y E. Saavedra (2003a): "Estructura de la Industria y Relaciones Patrimoniales del Gas Natural en Chile”, Documento de Investigación I-147, ILADESUniversidad Alberto Hurtado.

- (2003b): "Sustituibilidad de Energéticos y la Política (Des)Regulatoria del Gas Natural en Chile”. Documento de Investigación I-149, ILADES-Universidad Alberto Hurtado.

(2003c): "Mercados de Gas Natural: Análisis Comparado de la Experiencia Internacional”. Documento de Investigación I-150, ILADES-Universidad Alberto Hurtado.

Fuentes, R., R. Paredes y J. Vatter (1994): “Desregulación y Competencia en el Mercado de la Gasolina”. En Estudios Públicos 56 (primavera), 1-29.

Galetovic, A. (2003): “Integración Vertical en el Sector Eléctrico: Una Guía para el Usuario”. En Estudios Públicos 91 (invierno), 199-233.

(2008): “Un Análisis Económico de la Industria de la Distribución de Gas Natural en Chile”. Mimeo, Universidad de los Andes.

Gómez-Lobo, A. y F. Córdova (2006): "Los Precios de los Combustibles Líquidos a lo Largo del País: Posibles Explicaciones. S. En Arellano y S. Valdés (eds.), Los Mercados de Combustibles Líquidos en Chile. Ediciones P. Universidad Católica de Chile.

Green, E. y R. Porter (1984): “Noncooperative Collusion Under Imperfect Price Information”. En Econometrica 52, 87-100.

Grossman, S. y O. Hart (1986): "The Cost and Benefit of Ownership: A Theory of Lateral and Vertical Integration”. En Journal of Political Economy 94, 691-719.

Hall, R. (1988): "Intertemporal Substitution in Consumption”. En Journal of Political Economy 96 (2), 339-357.

Hölmstrom, B. y J. Roberts (1998): “The Boundaries of the Firm Revisited”. En Journal of Economic Perspectives 12 (4), 73-94.

Joskow, P. (1985): "Vertical Integration and Long-Term Contracts: The Case of CoalBurning Electric-Generating Plants”. En Journal of Law, Economics and Organization l (Spring), 33-80.

Katz, M. y H. Rosen (1985): “Tax Analysis in an Oligopoly Model”. En Public Finance Quarterly 13 (January), 3-19. 
Kreps, D. y R. Wilson (1982): “Reputation and Imperfect Information”. En Journal of Economic Theory 27, 253-279.

Kühn, K-U. (2001): "Fighting Collusion by Regulating Communication Between Firms”. En Economic Policy: A European Forum 0 (32), 167-204.

Milgrom, P. y J. Roberts (1982): "Predation, Reputation and Entry Deterrence". En Journal of Economic Theory 27, 280-312.

Nevo, A. (2001): “Measuring Market Power in the Ready-to-Eat Cereal Industry”. En Econometrica 69, 307-342.

Panzar, J. y J. Rosse (1987): “Testing for Monopoly Equilibrium”. En Journal of Industrial Economics 35, 443-456.

Selten, R. (1978): “The Chain Store Paradox”. En Theory and Decision 9, 127-159.

Shepard, A. (1993): "Contractual Form, Retail Price, and Asset Characteristics in Gasoline Retailing”. En RAND Journal of Economics 24 (1), 58-77.

Spengler, J. (1950): "Vertical Integration and Antitrust Policy”. En Journal of Political Economy 58, 347-352.

Stern, N. (1987): "The Effects of Taxation, Price Control and Government Contracts in Oligopoly”. En Journal of Public Economics 32, 133-158.

Vickers, J. (1995): “Competition and Regulation in Vertically Related Markets”. En Review of Economic Studies 62, 1-17.

Williamson, O. (1985): The Economic Institutions of Capitalism: Firms, Markets, Relational Contracting. New York: The Free Press. 